\title{
Is there room for resilience? A scoping review and critique of substance use literature and its utilization of the concept of resilience
}

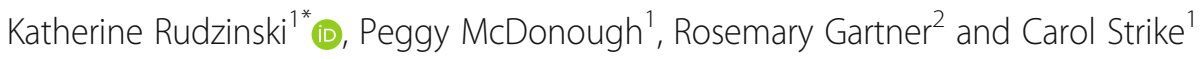

\begin{abstract}
Research in the area of illicit substance use remains preoccupied with describing and analyzing the risks of people who use drugs (PWUD), however more recently there has been a drive to use a strengths-based or resilience approach as an alternative to investigating drug use. This leads us to ask: what can be known about PWUD from the point of view of resilience? The objective of this scoping review is to analyze how the concept of resilience is defined, operationalized, and applied in substance use research. Popular health, social science, psychology, and inter-disciplinary databases namely: SCOPUS, PUBMED, PsycINFO, and Sociological Abstracts were searched. Studies were selected if they used the concept of resilience and if substance use was a key variable under investigation. A total of 77 studies were identified which provided a definition of resilience, or attempted to operationalize (e.g., via scales) the concept of resilience in some manner. Data were charted and sorted using key terms and fundamental aspects of resilience. The majority of studies focus on youth and their resistance to, or engagement in, substance use. There is also a small but growing area of research that examines recovery from substance addiction as a form of resilience. Very few studies were found that thoroughly investigated resilience among PWUD. Consistently throughout the literature drug use is presented as a 'risk factor' jeopardizing one's ability to be resilient, or drug use is seen as a 'maladaptive coping strategy', purporting one's lack of resilience. Currently, substance use research provides a substantial amount of information about the internal strengths that can assist in resisting future drug use; however there is less information about the external resources that play a role, especially for adults. Though popular, outcome-based conceptualizations of resilience are often static, concealing the potential for developing resilience over time or as conditions change. Studies of resilience among PWUD predominantly concentrate on health-related behaviours, recovery-related factors or predefined harm reduction strategies. Indeed, overall, current conceptualizations of resilience are too narrow to recognize all the potential manifestations of resilience practices in the daily lives of individuals who actively use drugs.
\end{abstract}

Keywords: Resilience, Substance use, Drug use, People who use drugs (PWUD), Strengths-based, Risk, Concept analysis

\section{Background}

Research in the area of illicit substance use remains preoccupied with describing and analyzing the deficits, vulnerabilities, and pathologies of people who use drugs (PWUD). This approach is not surprising, since PWUD, like other marginalized groups (i.e., homeless persons, sex workers), are simultaneously constructed as 'at risk'

\footnotetext{
*Correspondence: kat.rudzinski@mail.utoronto.ca

'Dalla Lana School of Public Health, University of Toronto, 155 College St,

Toronto, ON M5T 3M7, Canada

Full list of author information is available at the end of the article
}

in, and 'a risk' to, society [1]. Crack use is a case in point. It is commonly perceived as a pervasive criminal and public health problem which has been associated with: physical and mental health consequences (e.g., elevated risks of acquiring HIV and hepatitis $\mathrm{C}$ virus (HCV), antisocial personality disorder, major depression); discrimination, stigma, and isolation; and extremely high levels of poverty, homelessness, unemployment and crime [2-11]. Many people who smoke crack likely have experienced turbulent childhoods, high levels of parental drug use, and repeated instances of neglect as well as emotional, 
physical and/or sexual abuse [4, 12, 13]. Moreover victimization, including physical/sexual assault, robbery, and theft, among individuals who use crack is higher than in the general public, and also often elevated among other drug using groups [14-17].

Although the majority of studies on PWUD examine risk (e.g., [6, 18-21]), more recently there has been a drive to use a strengths-based or resilience approach as an alternative to investigating drug use. Resilience is most commonly defined as 'positive adaptation despite significant adversity' [22-24]. Over the years, resilience has been conceptualized in diverse ways: as a trait, as an outcome, and as a process; however, the most common uses of this concept remain outcome-focused [25-29]. Use of resilience terminology in social science research has boomed since the early 2000s [30]. Concurrently, the importance of social and cultural contextualization with respect to resilience also started to be emphasized [24, 31, 32]. Highlighting context is especially important for considering marginalized populations, and uncovering potentially hidden forms of resilience [33, 34].

It is clear that individuals who use crack are exposed to pervasive sources of trauma and adversity, yet there is indication that in spite of such experiences many individuals who use crack find ways to keep going, day after day. The daily hustle to make money, find or maintain housing, and score drugs provides evidence that individuals who use crack are not passive victims of their surroundings, but active participants in difficult circumstances $[4,11,35,36]$. Research details the ways in which crack-using individuals construct 'positive' identities (e.g., mother, hustler, dealer): garnering self-esteem, dignity, and respect for themselves on the streets, as well as taking pride in possessing a repertoire of interpersonal skills and street knowledge which aids their survival in a dangerous social environment [4, 37-40]. Additionally, individuals who use crack are cognizant of the risks of their environment and many make a concerted effort to avoid or minimize risks for themselves in a number of ways (e.g., using alone or with trusted others, leaving dangerous situations) [8, 41-44]. Even among the most victimized crack-using groups, joy in daily successes and hope for future endeavours have been reported $[36,45,46]$.

This example highlights the principle that drug use may not be synonymous with a lack of skills or potential. Unfortunately, this is the view most often portrayed in popular culture and academic research alike. Keeping in mind the significant strengths and accomplishments of individuals who use crack, especially under the direct stress and adversity often faced by this group, it is crucial to consider, what can be known about individuals who use crack, and other PWUD, from the point of view of resilience? This question provides the impetus for this review.

This scoping review provides an overview and critique of the utilization of the concept of resilience in the substance use literature. Specifically, this review analyzes how the concept of resilience is defined, operationalized, and applied in substance use research, and focuses on the core concepts of resilience research: adversity and risks, internal and external protective factors, and positive outcomes. Applications of resilience as a process, in the recovery field, and among active drug using groups are reviewed separately to highlight these important themes. The goal is to explore the strengths and limitations of the use of this concept, while also stressing significant knowledge gaps. Finally, the value, possible difficulties, and future potential of using resilience perspectives in the study of PWUD are discussed.

\section{Methods}

For this scoping review popular health, social science, psychology, and inter-disciplinary databases, namely: SCOPUS, PUBMED, PsycINFO, and Sociological Abstracts, were searched using various combinations of the terms: resilience, resilient, resiliency, resilience theory, drug use, drug user, substance use, addiction, and dependence. A hand-search of the reference lists of included papers was also conducted. To ensure the most current review of the literature, the focus is placed on studies published within the past 16 years. This is an appropriate temporal scope for review as it coincides with the push for contextualization in resilience research as well as a rise in popularity of the use of this concept in substance use and related fields [24, 30-32]. Studies were chosen if:

1) the term resilience is used, in the title, abstract, or keywords; and,

2) substance use/addiction is a main variable considered in the study.

The focus of this review is primarily on sociological and psychological studies, thus any biological, genetics, and neurosciences research is left out of the analysis. Special care is taken to identify any studies that look at active, illicit drug using populations (e.g., marijuana, cocaine, crack, heroin, opiates, etc.). Studies focusing solely on alcohol or cigarette use are also omitted in order to narrow the scope of this review, and to bring attention to the contentious relationships between illegal drug use and resilience. This review was also limited to studies of PWUD, thus omitting studies on children of drug users. Where inclusion was solely based on evidence of a substance using population, PWUD had to represent a majority, defined as $60 \%$ or more, of the population under investigation. Additionally, this review focuses on individual level resilience, where the majority of research is concentrated, rather than family or community-level resilience (e.g., [47-50]). Data were charted and sorted 
using key terms and fundamental aspects of resilience present in the studies of interest, and reported within the general resilience literature [51]. Based on this, the following themes were derived and will be explored here: definitions and operationalizations, adversity and risk, protective factors, resilience outcomes, process-based conceptualization of resilience, resilience and recovery, and resilience and PWUD.

\section{Results}

A total of 396 studies were retrieved. However, from this group, 319 are excluded because they do not substantially add to the analysis of resilience in the substance use field. Many provide no definition, theoretical backing, or operationalization of resilience (e.g., [52-58]). Others use resilience as a synonym for 'restraint' from drug use [59-62], or as a descriptor for individual(s) who adapt well or display toughness [11, 46, 63-65]. The remaining 77 studies selected provide a definition of resilience, or attempt to operationalize (e.g., via scales) the concept in some manner (Table 1).

The majority of studies focus on youth and their resistance to, or engagement in, substance use. While most of this research focuses on inner-city high school adolescents, studies have also been conducted with affluent youth, young adults in university cohorts, foster youth, and institutionalized adolescents. There is also a small but growing area of research that examines recovery from substance addiction as a form of resilience, and a few studies of unique populations, such as: adults with former childhood experiences of trauma, Aboriginals, veterans, incarcerated individuals, men who have sex with men, street-based individuals, sex workers and PWUD. Several reviews of resilience to drug use among youth were also identified. They are used for further theme development, and cross-referenced to ensure inclusion of all relevant work [66-74].

\section{Definitions and operationalizations of resilience}

Due to the difficulties in defining and operationalizing resilience in the broad literature, it is not surprising that researchers within the field of substance use also experience some complications [24, 27, 75]. This scoping review identified several key types of resilience definitions cited (Table 1). The most commonly cited is the standard definition proposed by Luthar et al. [24] and Masten $[22,23]$ : 'resilience is positive adaptation in spite of adversity'. Sometimes the level of adversity is qualified as 'significant', 'severe', or 'extreme' to underline the exceptionally difficult circumstances study participants had to deal with (e.g., physical/sexual abuse, family violence) (e.g., [76-78]).

Another type of definition utilized in the substance use literature is process-based. For example resilience defined as: "the process of effectively negotiating, adapting to, or managing significant sources of trauma" ([79], p. 2). Or in another instance, resilience as "a developmental process wherein the individual is able to utilize resources in and outside the self to negotiate current challenges adaptively and, by extension, to develop a foundation on which to rely when future challenges occur" ([80], p. 472). However, the definition presented and the usages of the concept throughout the study do not always align. For instance, some authors provide a process-based definition, but rely on a trait or outcomebased operationalization with no dynamic elements. These studies put more emphasis on which factors foster resilience, rather than investigate the process of how or why they do (e.g., [81-85]).

Sometimes resilience is defined in relation to the specific outcomes being studied. For instance, Eisen and colleagues [86] define resilience for army veterans as "the ability of adults who are exposed to highly stressful events, such as the violent, life threatening situations encountered in combat, to maintain healthy psychological and physical functioning [including absence of drug use]" ([86], p. 755). Although such limited definitions are clear, their restricted range can sometimes obscure evidence of hidden forms of resilience. Conversely, a more productive approach for defining resilience, especially for marginalized populations, has been to use open-ended definitions (e.g., $[79,87])$ which take into account the context and environmental constraints, allowing for more nuanced and hidden forms of adaptation to adversity to be considered as practices of resilience. These types of definitions and their benefits will be taken up in more detail in the process-based conceptualizations of resilience and PWUD and resilience sections of this review.

The most common operationalization of resilience is as the presence of positive adaptations or absence of negative outcomes. Generally researchers are looking for the absence of drug use which signifies the presence of resilience. While this form of operationalization is direct, it can also be quite restrictive. The various configurations, strengths and drawbacks of outcome operationalizations will be discussed in the resilience outcomes section.

Scales are also often utilized to operationalize resilience in the substance use field, most commonly versions of the Connor-Davidson Resilience Scale (CD-RISC) or the Wagnild \& Young Resilience Scale (RS) (Table 1). Although scales are a straightforward and consistent approach to operationalizing resilience, many are overly focused on individual level traits, characteristics, and skills. For example, common items include ego strength, sense of purpose, goal-orientation, self-efficacy, self-esteem, hardiness, tenacity, self-mastery, optimism, spirituality/faith, adaptive coping, problem-solving skills, cognitive flexibility, 


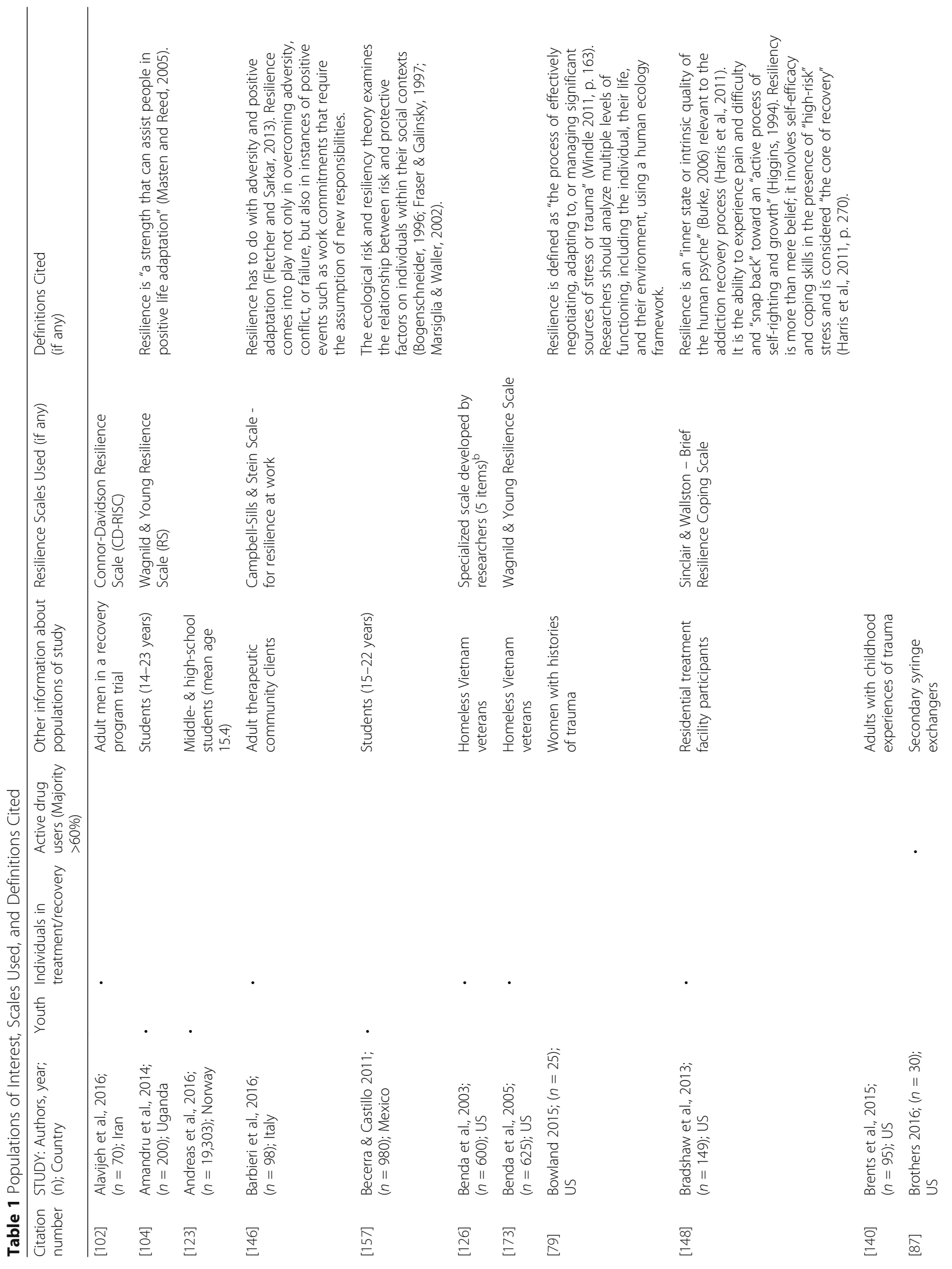


Rudzinski et al. Substance Abuse Treatment, Prevention, and Policy (2017) 12:41

Page 5 of 35

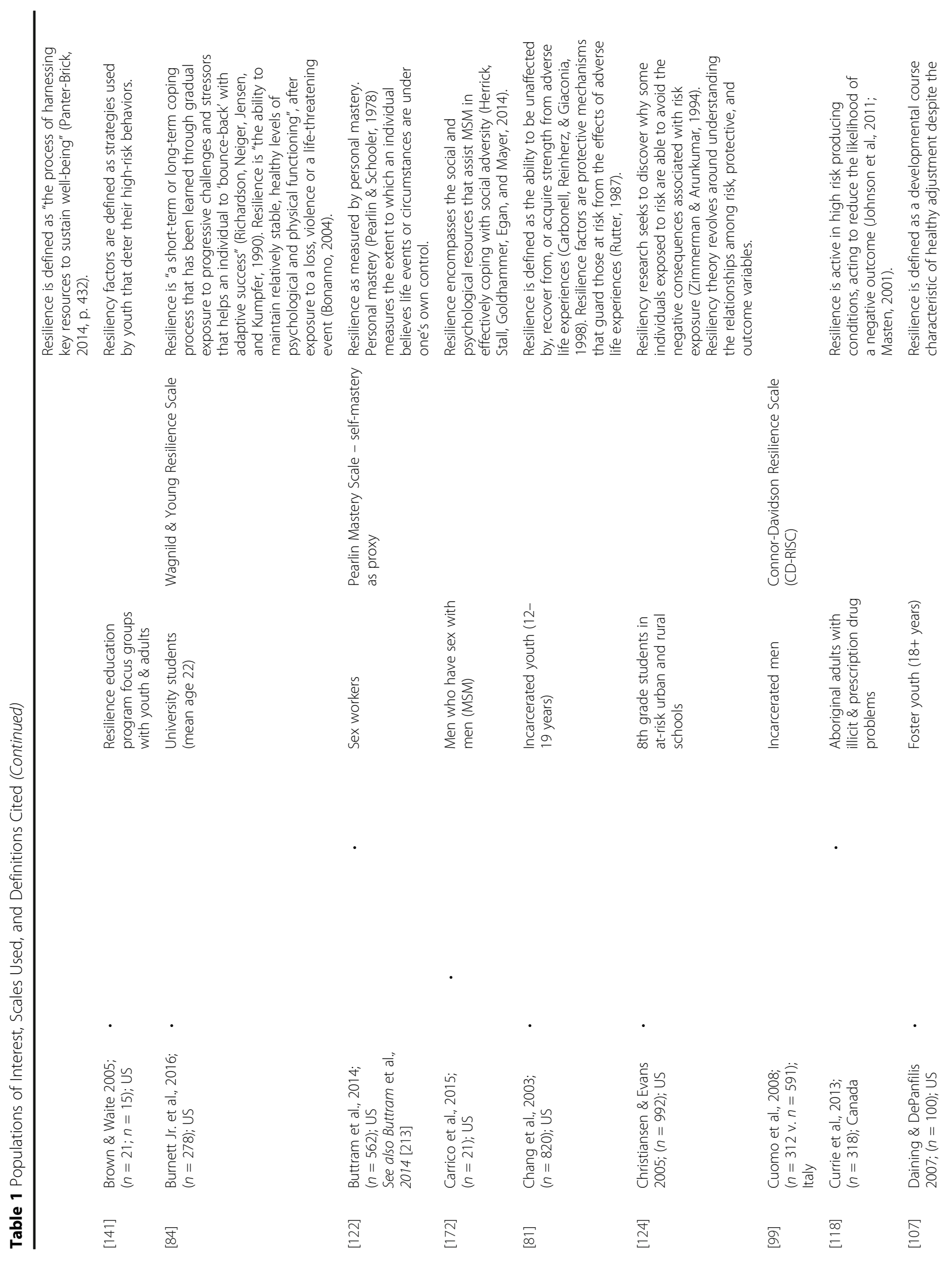




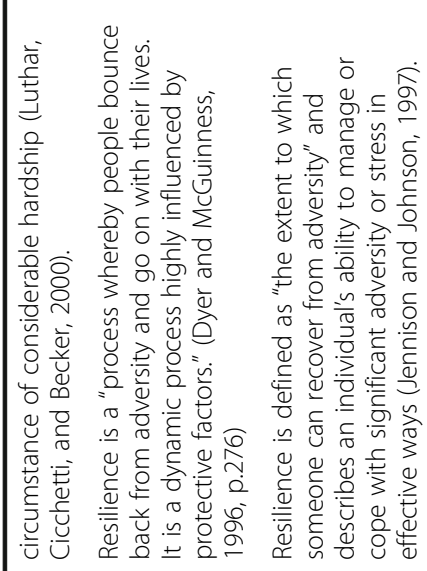

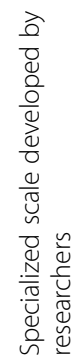

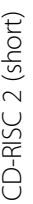

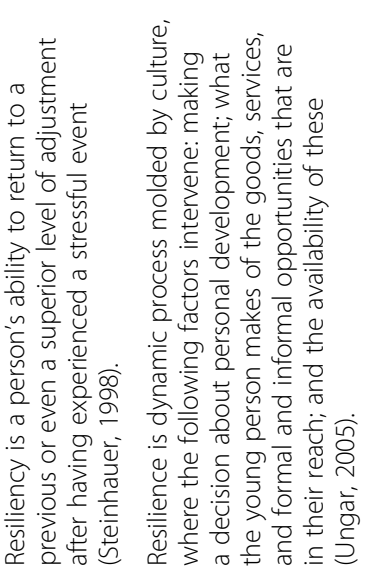

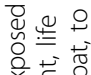

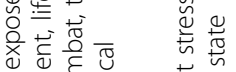

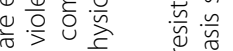

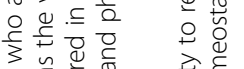

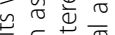

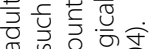

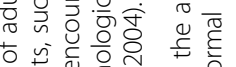

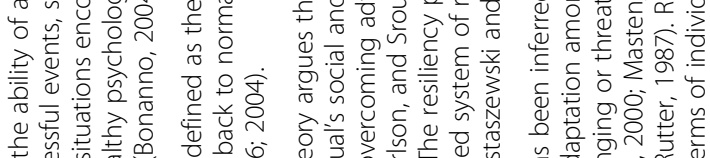

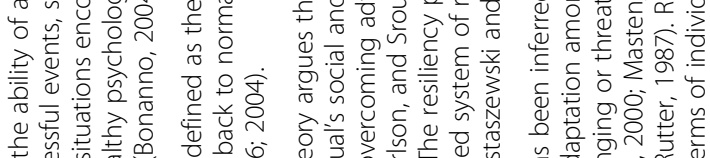

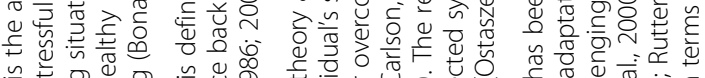

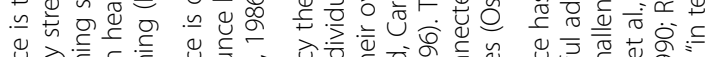
论

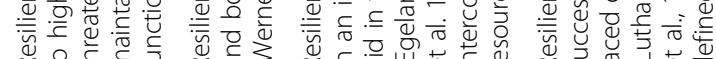

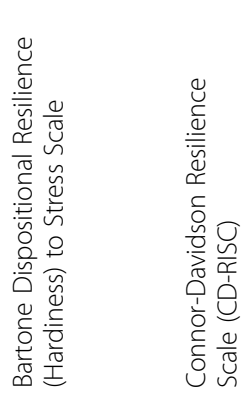

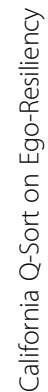
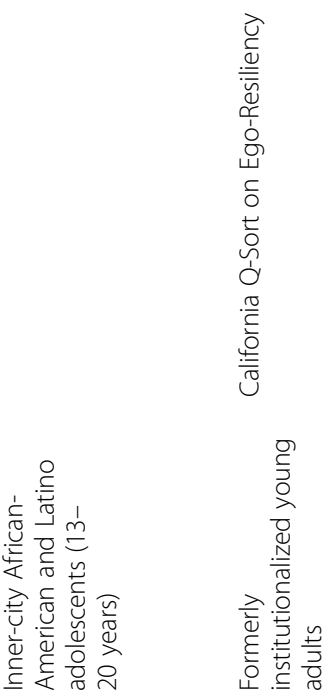

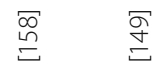

$\stackrel{\infty}{\Xi}$

$\underset{\infty}{\infty}$

$\stackrel{\Xi}{\Xi} \quad \stackrel{\Xi}{\Xi}$

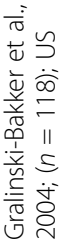

$\underset{\varpi}{\varpi}$

$\stackrel{\bar{m}}{\Xi}$

羿

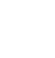




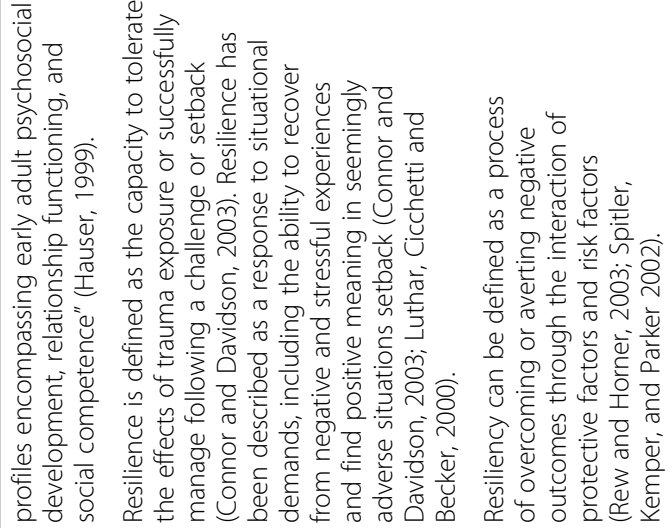

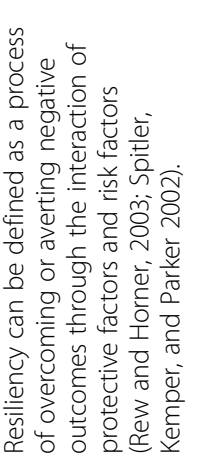

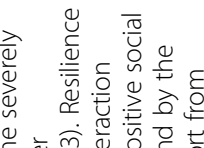

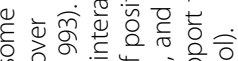

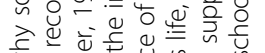

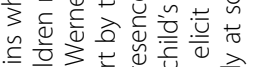

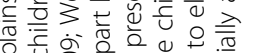

区थ

ษ.

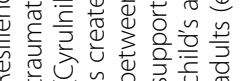

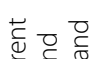

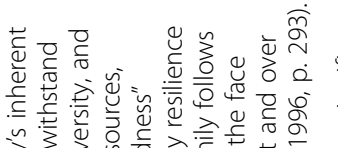

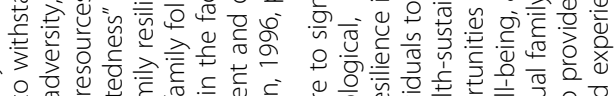

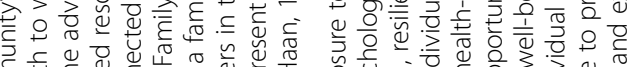

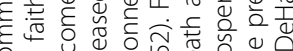

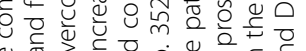

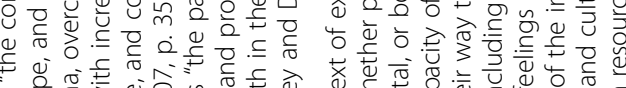

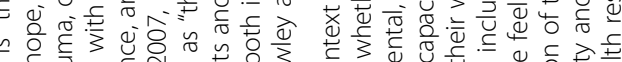

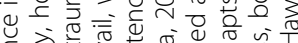

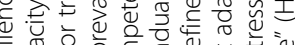

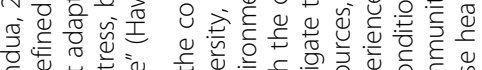

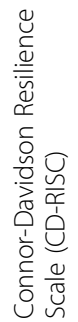
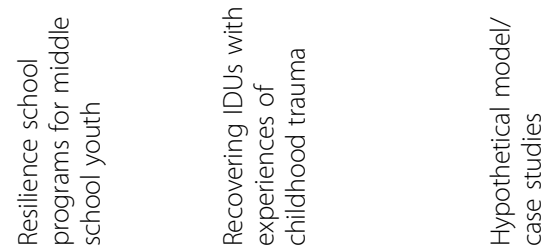

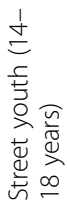
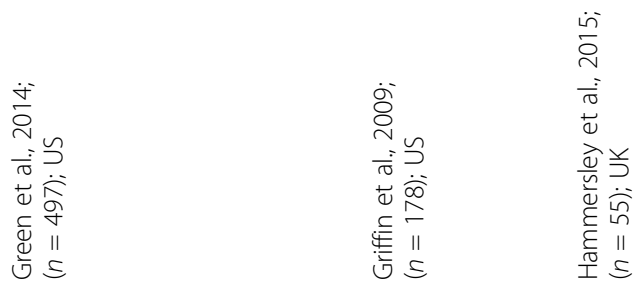

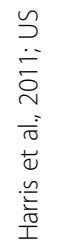

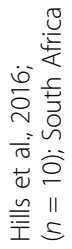

$\stackrel{\Xi}{\Xi}$

잉

$\stackrel{\text { ษ }}{\Xi}$

$\stackrel{\infty}{\Delta}$ 
Rudzinski et al. Substance Abuse Treatment, Prevention, and Policy (2017) 12:41

Page 8 of 35

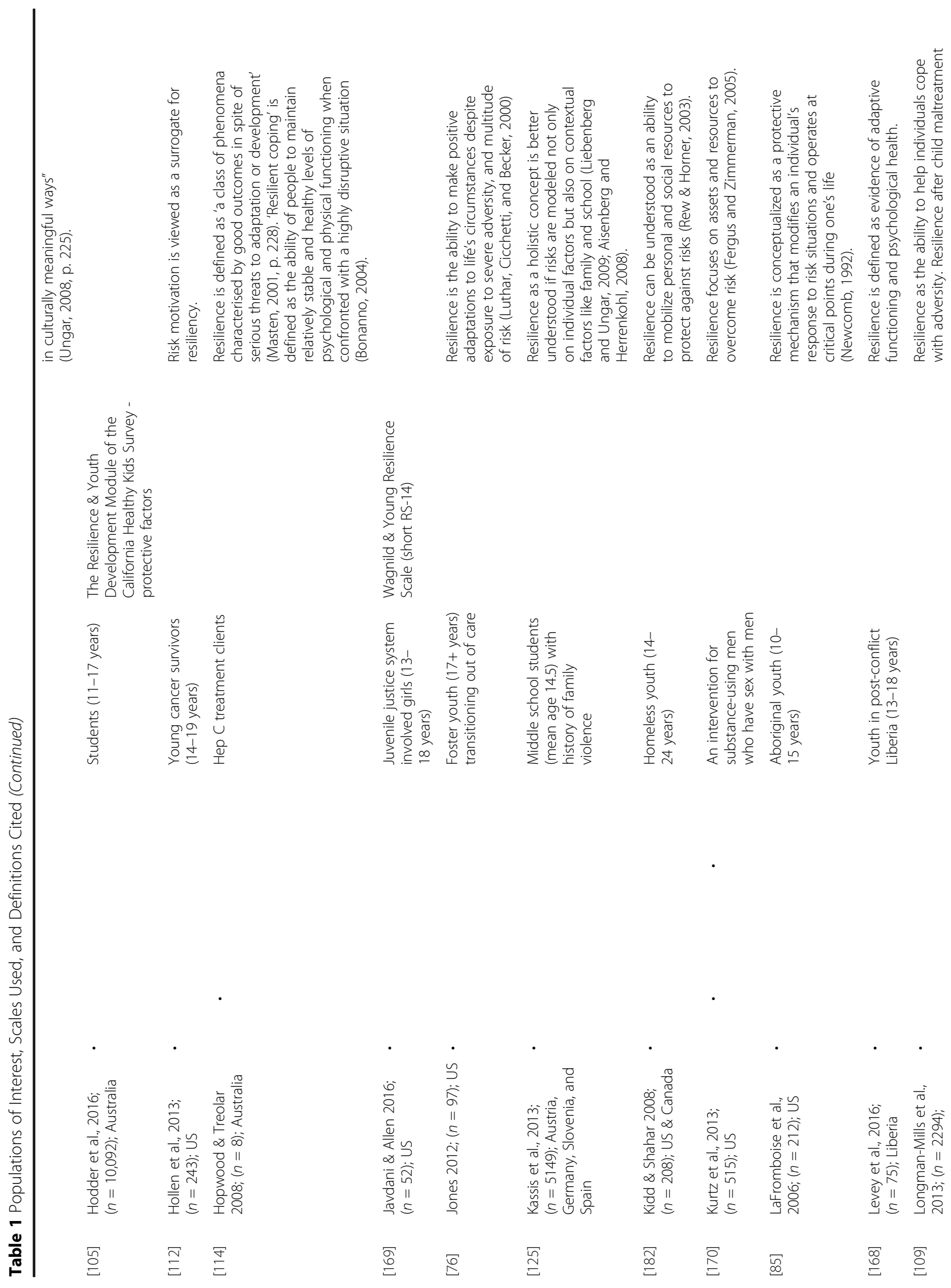


Rudzinski et al. Substance Abuse Treatment, Prevention, and Policy (2017) 12:41

Page 9 of 35

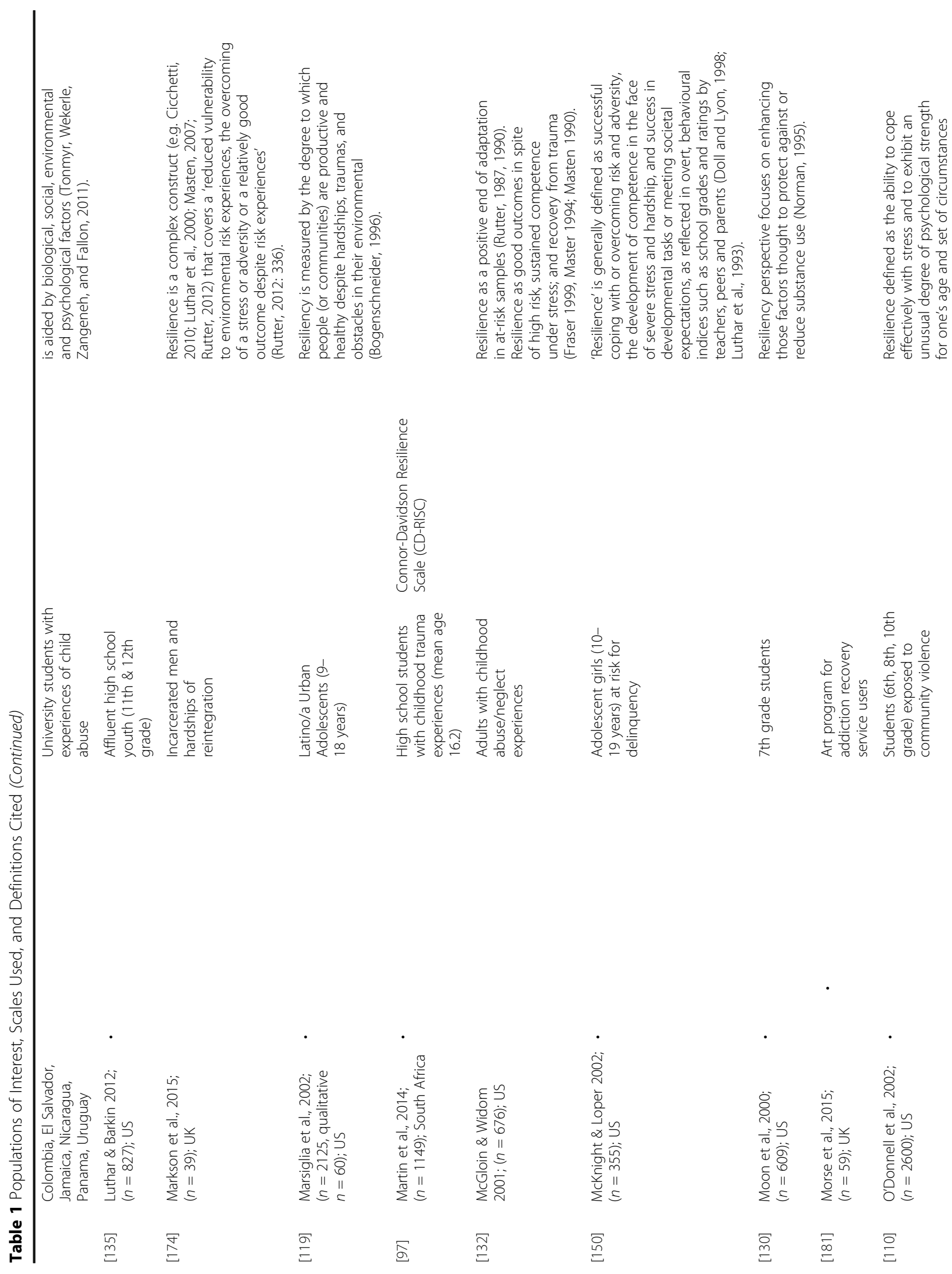


Rudzinski et al. Substance Abuse Treatment, Prevention, and Policy (2017) 12:41

Page 10 of 35

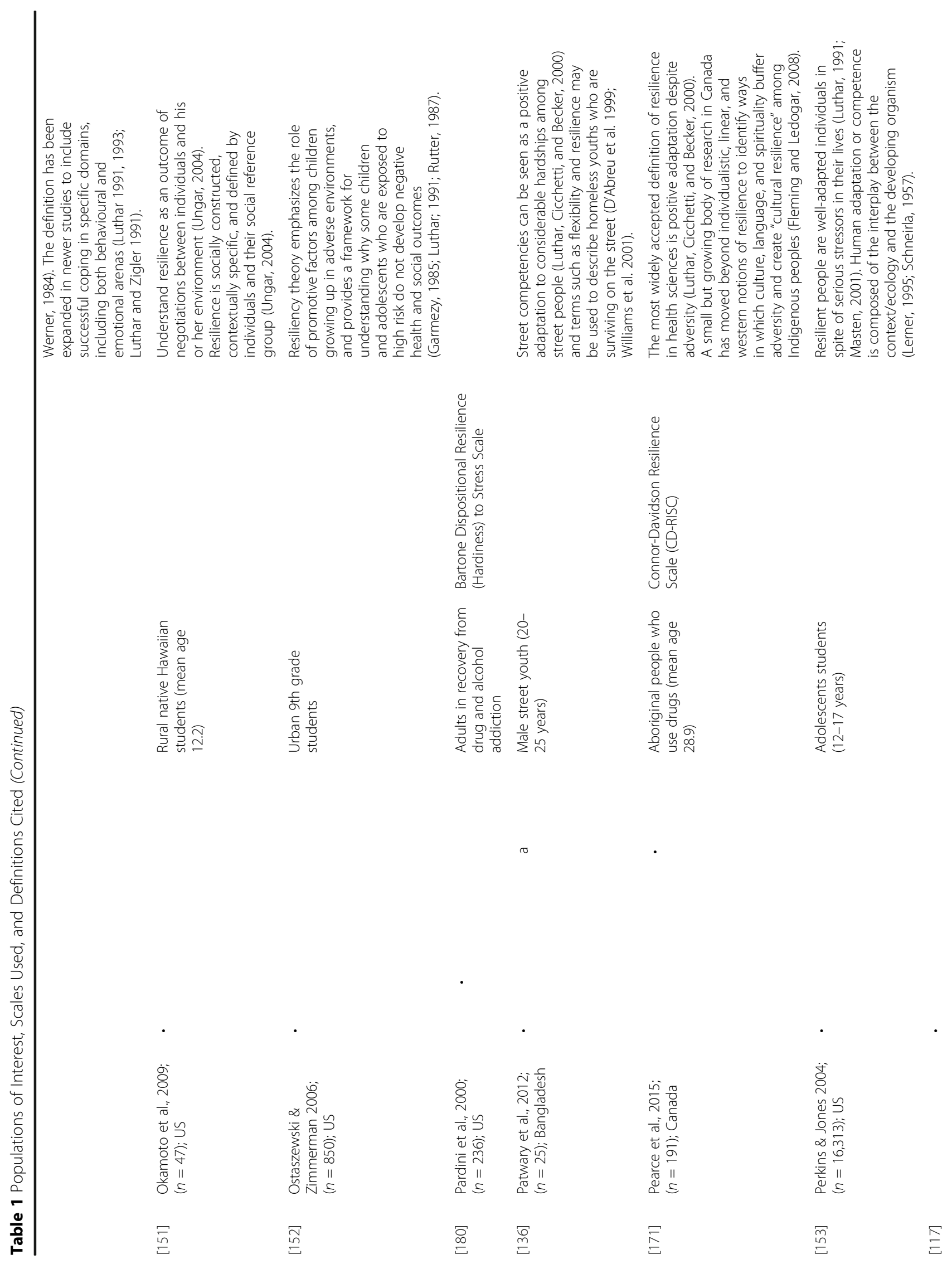


Rudzinski et al. Substance Abuse Treatment, Prevention, and Policy (2017) 12:41

Page 11 of 35

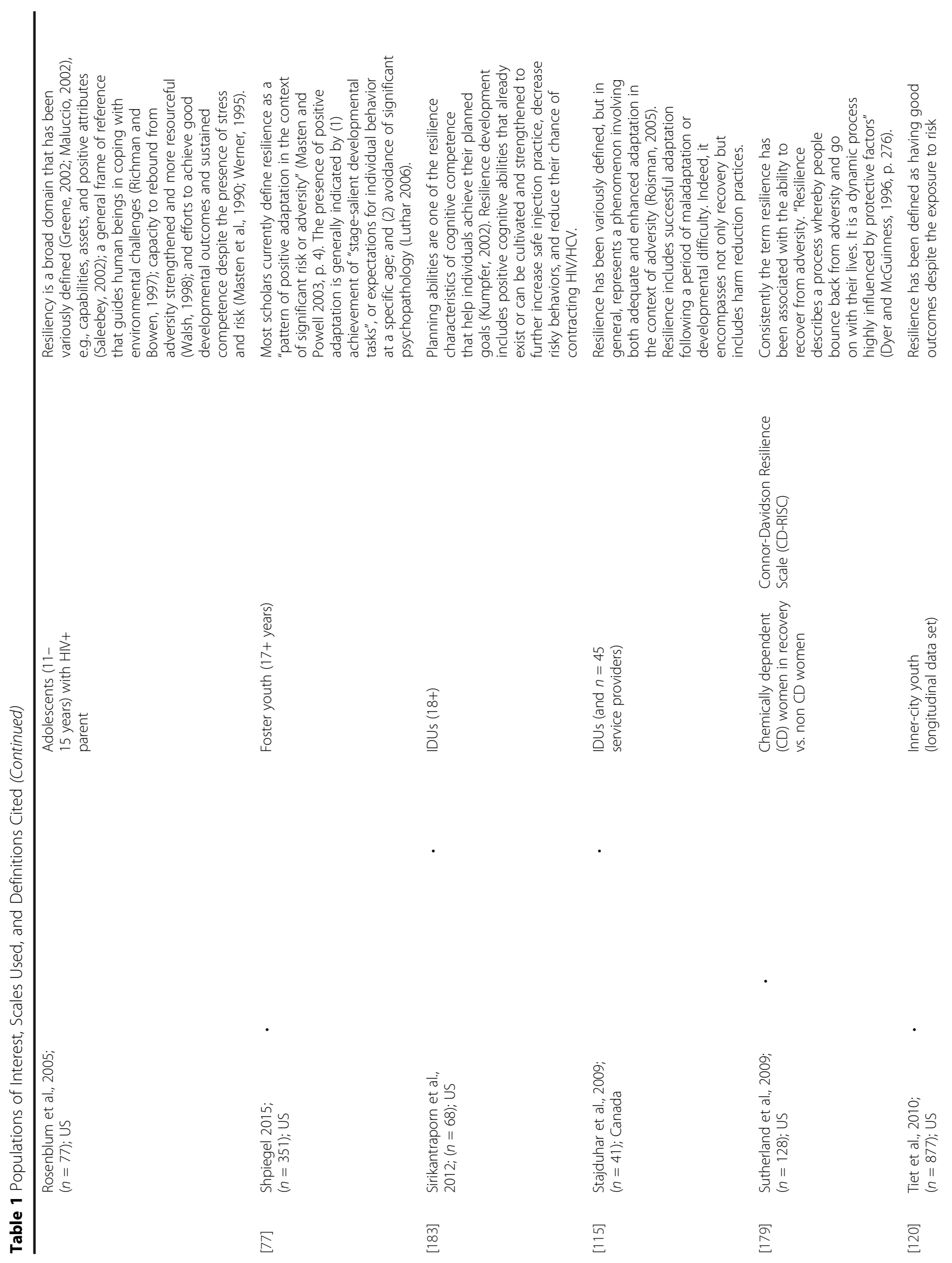


Rudzinski et al. Substance Abuse Treatment, Prevention, and Policy (2017) 12:41

Page 12 of 35

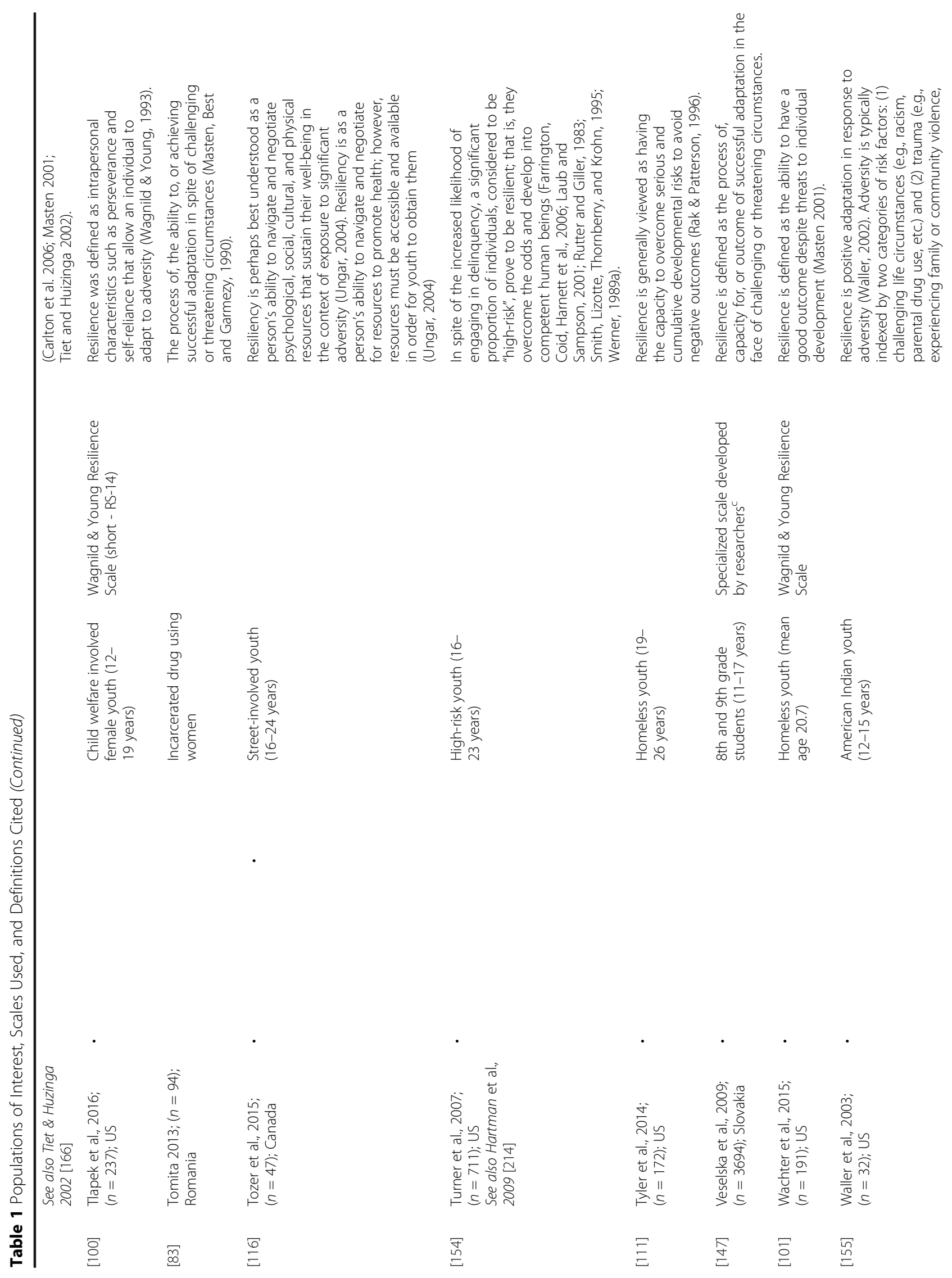


Rudzinski et al. Substance Abuse Treatment, Prevention, and Policy (2017) 12:41

Page 13 of 35

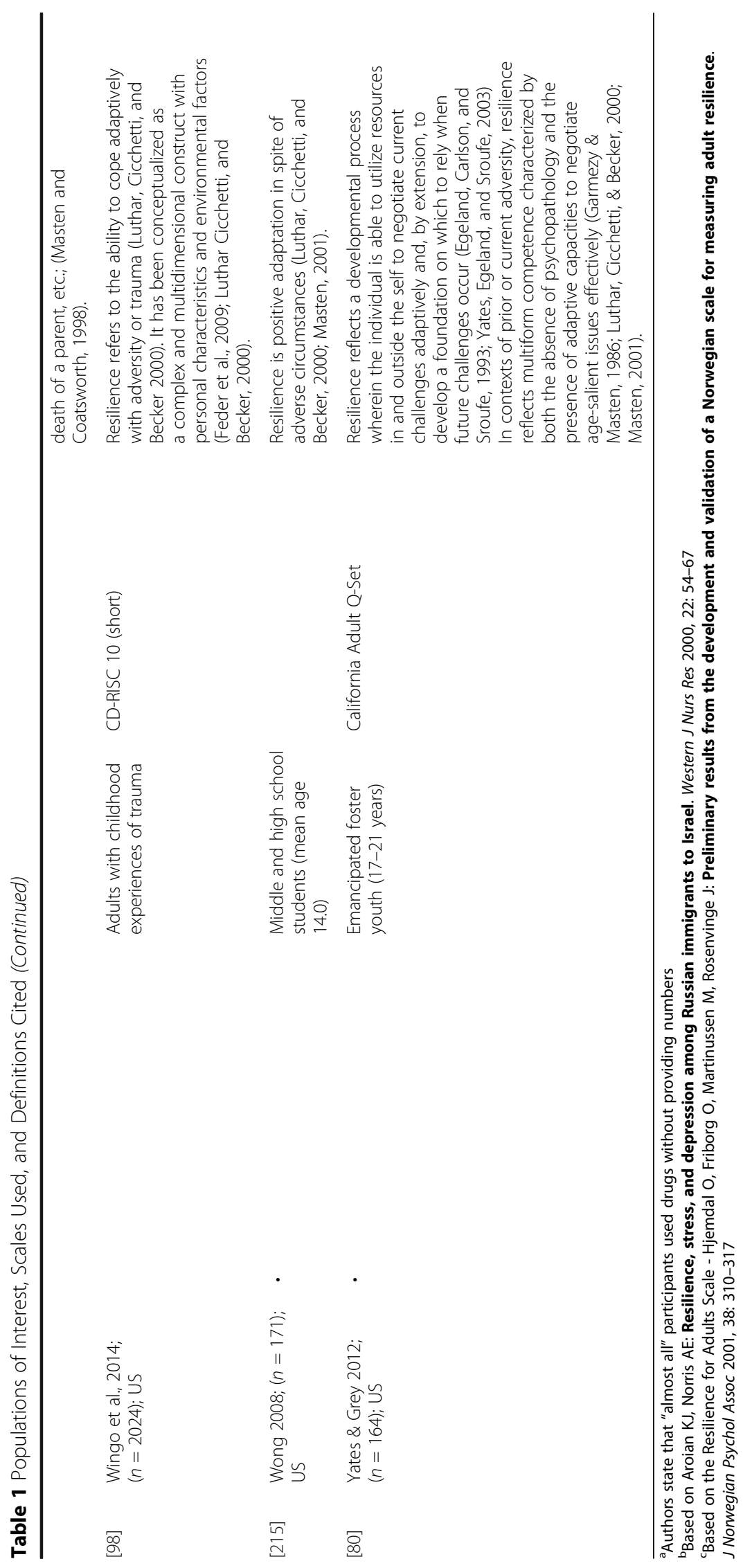


educational expectations, empathy, and sense of humour [88-94]. Although the CD-RISC includes aspects such as secure relationships and knowing how to facilitate social support, while the RS considers an individual's need for social approval, companionship and assistance, both of these scales are still primarily focused on individual-level factors [88, 92, 93, 95]. So essentially when utilizing such scales researchers are putting considerable weight on the individual-level aspects of resilience, and performing traitbased examinations. As such, they leave out much, or any, notion of other salient factors (e.g. external resources, environmental circumstances) that could affect measurements of resilience.

Interestingly the majority of authors who adopt a traitfocused conceptualization of resilience rely on resilience scales (e.g., [84, 96-103]). They account for a third of all scale usage in this scoping review. In contrast, a number of authors recognize the limitations of trait-focused resilience scales in capturing the concept holistically, and adapt by measuring external protective factors as well. For instance, in addition to using the RS, Amandru et al. [104] also look at the effects of social support, which include informational, tangible and affectionate support as well as positive social interactions with family and peers. Another exception to these trait-focused scales is Hodder and colleagues' [105] study of resilience to drug use among students, where the researchers make use of the Resilience and Youth Development module of the California Healthy Kids Survey, which measures both internal assets and external resources, such as family, school and community engagement.

Resilience research is wrought with definitional and operationalization difficulties. This concept is typically operationalized through outcomes measuring the occurrence of positive, or the lack of negative, adaptations. When process-based definitions are provided their usage of the concept throughout the research does not always align. Scales are also often utilized to operationalize resilience, yet many are overly focused on individual level factors. Many authors who subscribe to a trait-focused conceptualization of resilience rely on resilience scales, while others recognizing the limitations of this approach adapt by measuring external factors as well.

\section{Adversity and risk as precursors of resilience}

A necessary antecedent of resilience is adversity, with researchers often asking the important question: resilience with respect to what? [106]. This scoping review found three main categories of adversity: traumatic events, disease processes, and daily stressors. Traumatic events include physical, sexual, and emotional abuse, childhood maltreatment/neglect, violence, and criminal victimization (e.g., $[78,79,84,97,98,100,107-111])$. Disease processes under investigation encompass addiction, mental health problems, HCV/HIV progression, and cancer diagnosis (e.g., [112-117]). Daily stressors often overlap with other risk factors considered, and comprise conditions or experiences such as living in high risk neighbourhoods, poverty, homelessness, discrimination, school problems, family discord, and transitioning out of foster care (e.g., $[76,77,85,87,111,118-122])$. Drug use is often considered a daily stressor or risk factor for resilience for the individuals under investigation (e.g., [80, 123-126]).

The intensity and duration of adversity exposure is crucial when studying resilience [30, 127], yet only a few studies explicitly measure the levels of adversity and differences in exposure between study participants. For example, O'Donnell et al. [110] differentiate between students who witness community violence and those who are personally victimized, when measuring their respective risk for drug involvement. Meanwhile, Duque and his fellow researchers [128] ascertain a minimum level of risk exposure among Colombian youth, by defining a resilient youth as: "one that has experienced three or more risk factors but has not presented any of the severe aggressive behaviors or any of the other risky behaviors... [including drug use]" ([128], p. 2212).

In contrast to these studies, several do not explain how adversity is measured. This type of 'taking adversity for granted' occurs most often in studies of student drug use, where the reader is left to assume that the threat facing students is the social influence to try drugs [82, 96, $105,129]$. The dilemma with this approach is that since it is not measured how often, if ever, these youth are offered drugs, it is "impossible to assess whether or not these students had to bounce back from adversity and go on with their lives" ([82], p. 18). This is not the case in all student studies. For instance, Moon et al. [130] attempt to quantify the 'threat of drug offers' for students by looking at the event from several key vantage points. These researchers ask youth about ever having been offered drugs, the context of the last offer (i.e., location of offer: school, party, park, street, friend's home, own home), and the age of first use. Likewise, Andreas et al. [123], in their study of 'who says no to cannabis offers', consider three groups of students: cannabis users, cannabis naïve (those who have never received an offer to use) and cannabis resilient (those who decline offers for cannabis); thereby expanding the research of protective factors beyond the overly simplistic dichotomy of cannabis user vs. non-user. Nonetheless, the threshold for adversity in resilience research continues to be a point of contention [131, 132]. As Fletcher et al. [131] explain, some researchers state that adversity must include a significant negative life event(s), known to be "statistically associated with adjustment difficulties" ([133], p. 858), while others view adversity less strictly, allowing it to encompass any type of hardship, misfortune or difficulty $[131,134]$. 
Although it is very important for authors to be clear about the adversity facing their populations of interest, some researchers take this to the extreme and continue to over-focus on risk and adversity (e.g., [83, 108, 135, 136]). For example, Tomita's [83] study of drug using women prisoners claims to look at protective factors to improve resilience and reintegration into the community after release. However, a considerable portion of the paper categorizes and discusses the various risk factors for addiction these women face inside and outside of prison. Resilience on the other hand, is presented as a future goal, defined and contextualized in previous research, but not used to analyze the current data. Thus, resilience in some of these risk-focused studies is treated as an adjunct or after-thought rather than being utilized to its full potential as a concept.

This scoping review found that drug use is often treated as a daily stressor or risk factor for resilience. Only a few studies investigate the intensity and duration of adversity exposure. A disagreement concerning the necessary level of adversity continues in the literature whereby, some investigators only focus on resilience to major life misfortunes, while other researchers investigate evidence of resilience to any type of difficulty. Problematically, a number of researchers take adversity for granted, typically in student studies where the assumption is: adversity is the negative social influence to try drugs.

\section{Internal and external protective factors}

Protective factors are internal strengths and external resources that interact with risks to affect the chances of negative outcomes for individuals [69, 137, 138]. In this field, a substantial number of researchers continue to see resilience as an "inner state or intrinsic quality of the human psyche" ([139], p. 284), with some authors emphasizing the psychological and personality aspects of resilience against drug use (e.g., [96, 111, 112, 140]), while others discuss the need for a resilient constitution or skill set to resist involvement with drugs (e.g., [73, $102,109,141])$. In essence, when focusing on individuallevel factors, resilience is presented as an attribute that 'must be' developed (e.g., through resilience education/ school programs) or maintained (e.g., throughout addiction recovery) $[66,129,142]$.

Commonly considered internal factors include: selfesteem, self-efficacy, personal skills (e.g., coping, problem solving, social, help seeking), intellectual ability, religiosity/spirituality, and optimism, (Table 2). One unique, drug-specific internal factor considered is 'attitudes about drug use', which focuses on such elements as: fear of consequences of drug use (i.e. health problems, parental disapproval), belief that drugs will interfere with one's future goals, anti-drug personal norms, and no interest in drug use [82, 112, 117, 119, 121, 123, 141].
There is value in highlighting the inner strengths of individuals in overcoming adversity as, for example, Dell et al. [143] do so by discussing strengthening the inner spirit and cultural connectedness of Aboriginal youth overcoming solvent addiction. The problem is that not all researchers discuss how resilience may be strengthened or weakened by interactions (and choices) between the individual and their potential external resources [108]. Moreover, a restrictive emphasis on individual-based resilience can lead to some problematic dichotomies. For instance, 'resilient' individuals are seen as having 'what it takes' to refrain from drug use, while those 'non-resilient' persons who 'succumb' to addiction are seen as weak, deficient and blameworthy [37, 144, 145]. These types of studies reinforce dominant negative opinions of PWUD and, as Kassis et al. [125] warn, perpetuate further 'victim-blaming'.

Numerous studies on substance use utilize the term 'resiliency', often interchangeably with 'resilience' (e.g., [76, 82, 100-102, 109, 111, 112, 119, 121, 124, 129, 130, 141-143, 146-155]. This inconsistent use of terminology occurs in spite of multiple warnings from long-time resilience researchers, that choosing 'resiliency' terminology suggests an intrinsic quality of the person rather than the achievement of positive outcomes based on various levels and interactions of protective factors and resources [23, 24, 132]. Additionally, resilience is often equated with protective factors in the substance use literature. The term 'resilience factor' is often used interchangeably with 'protective factor' (e.g., [81, 109, 117, 118, 147, 150]), further adding to the conceptualization of resilience as a static factor(s), rather than a dynamic concept dependent on both protective and risk elements. Given the fact that the field of resilience research is already fraught with definitional and operationalization difficulties, consistency or, at minimum, clarity in the use of terminology within and across disciplines is crucial.

Moving beyond internal traits and characteristics, many studies in the field of substance use also consider external resources for resilience, at three broad levels: family, school and community. Frequently explored external protective factors at the family level are: parental supervision, family management (e.g., setting boundaries and appropriate consequences) family support (e.g., trust, adaptability, and cohesion), family bonding (e.g., closeness, communication, and cultural ties), and support from a partner. At the school level researchers look at: positive school environment, good relationships with teachers, school engagement, involvement in extra-curricular activities, and positive peer connections. Finally, at the community level community engagement, supportive relationships with friends or community members (e.g., neighbours, case workers), participation in religious/spiritual practices, and formal community supports (e.g., social services, addiction programs, housing) are considered (Table 3 ). 







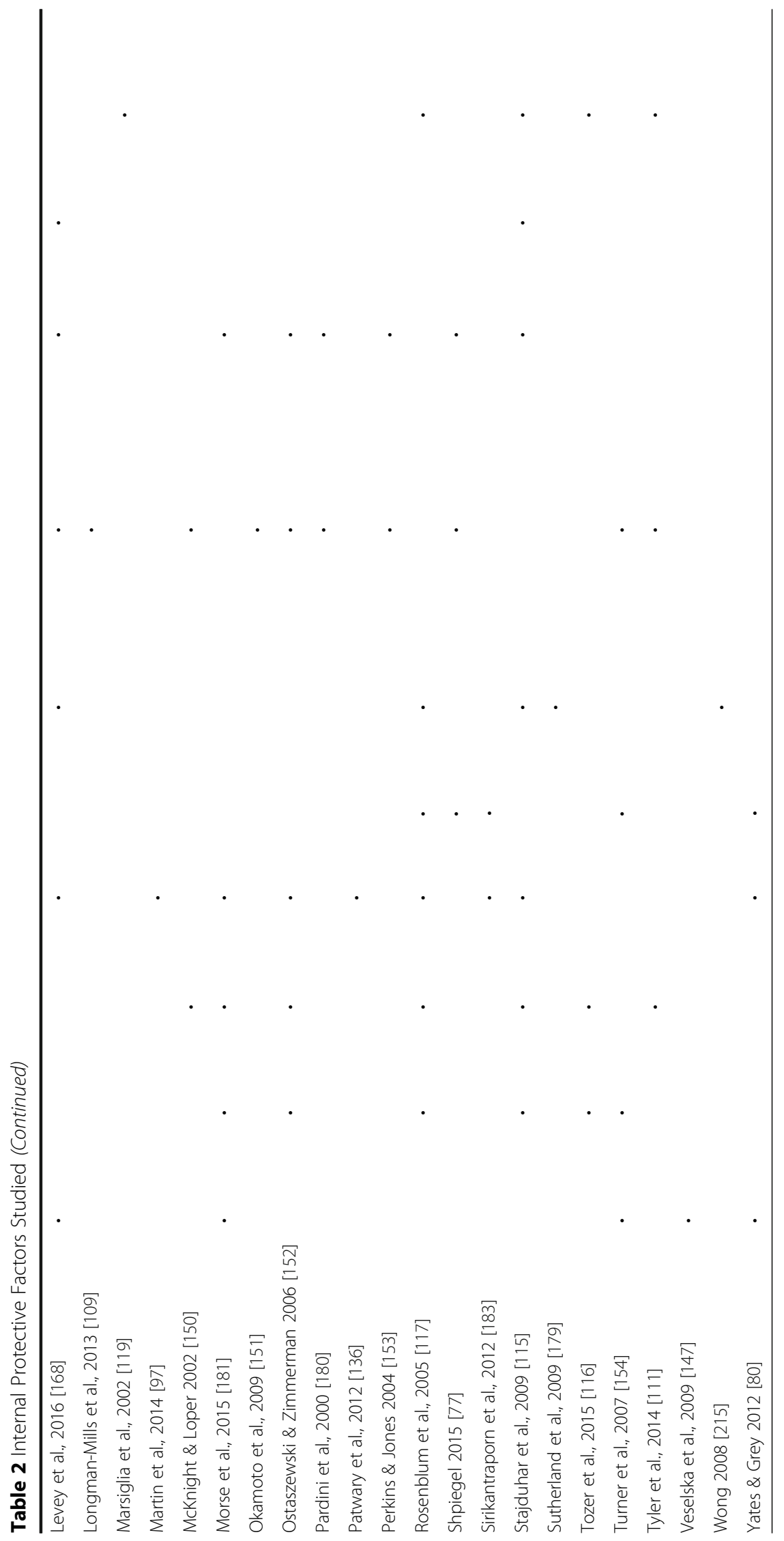




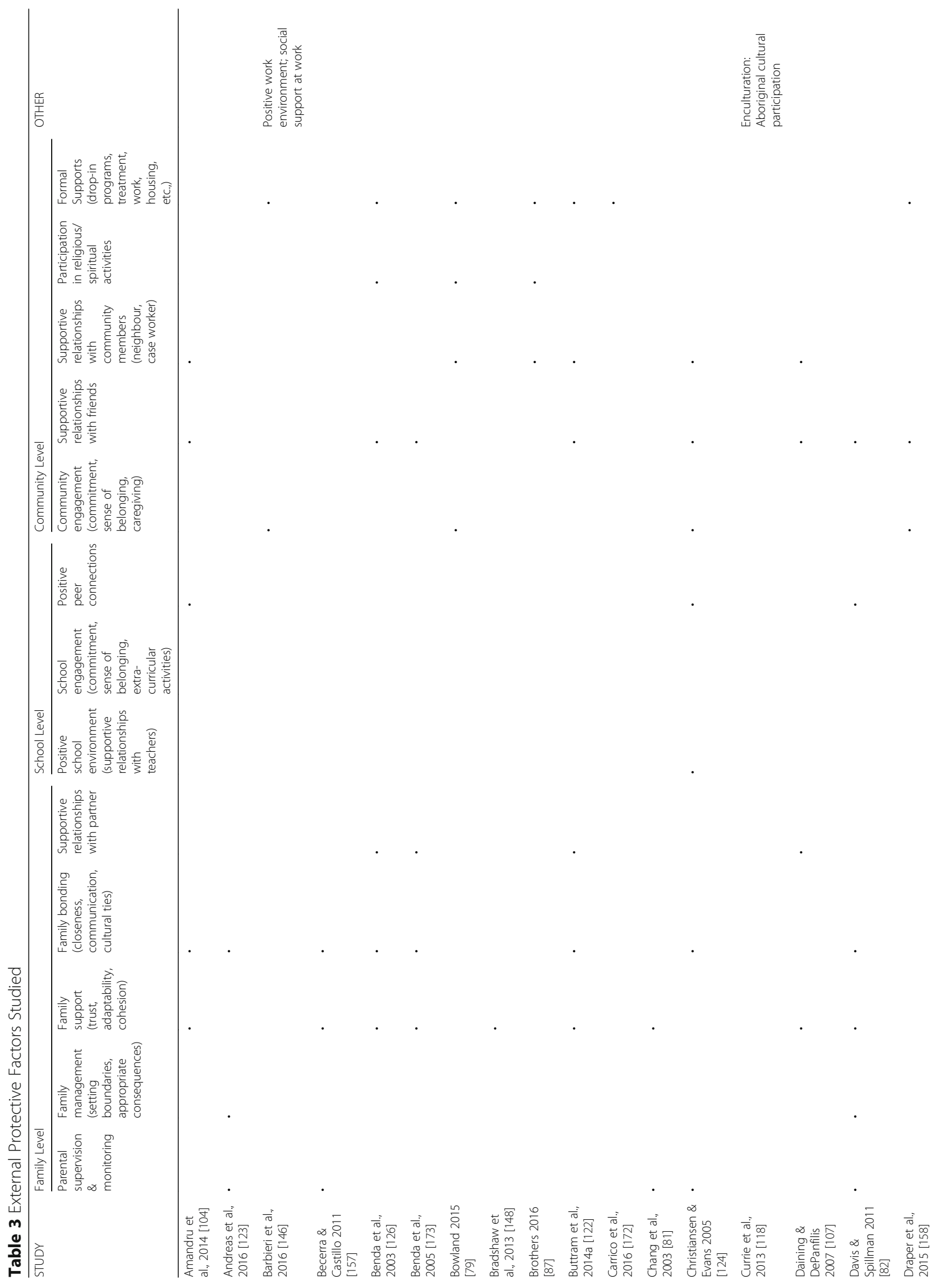




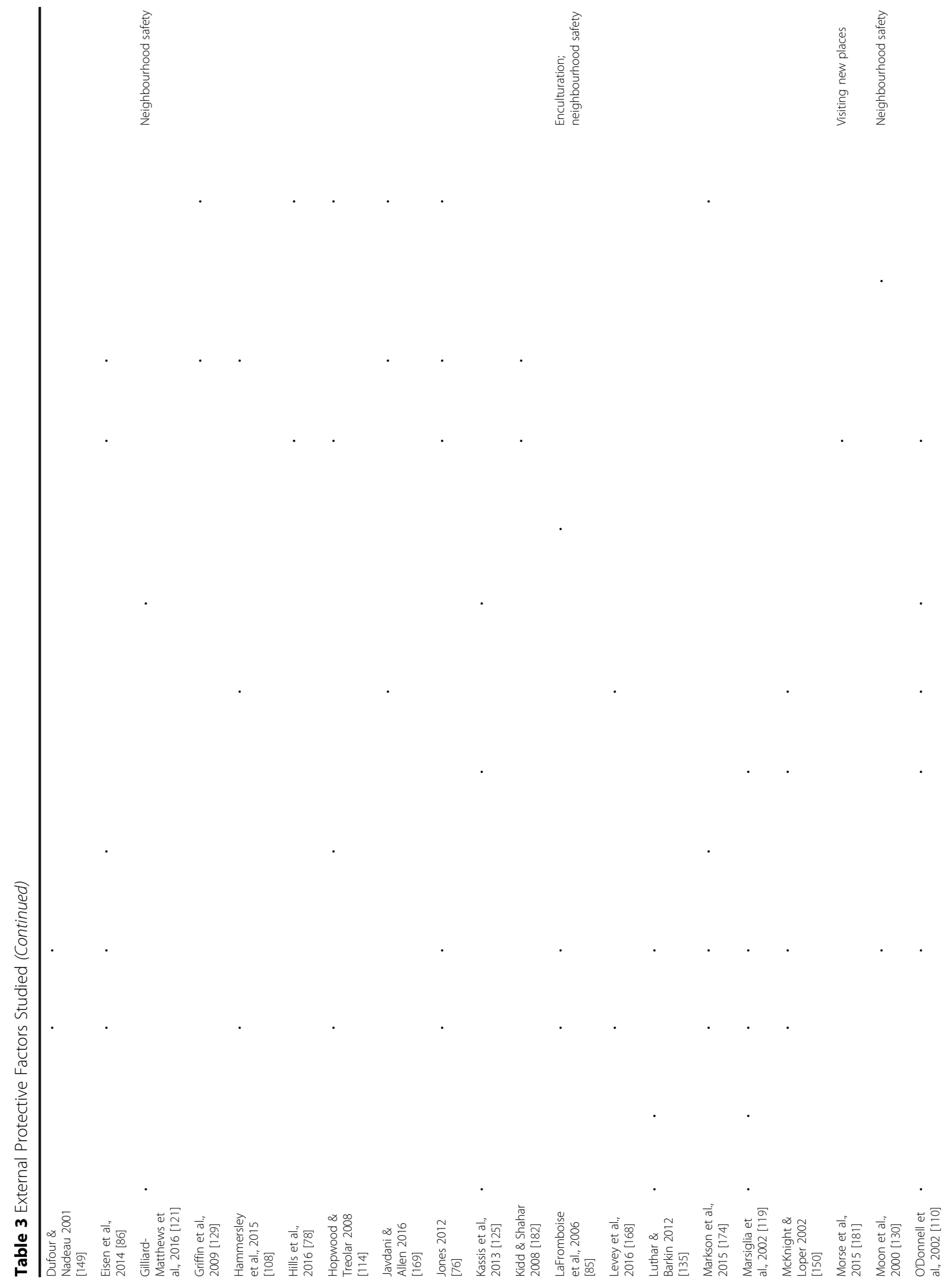




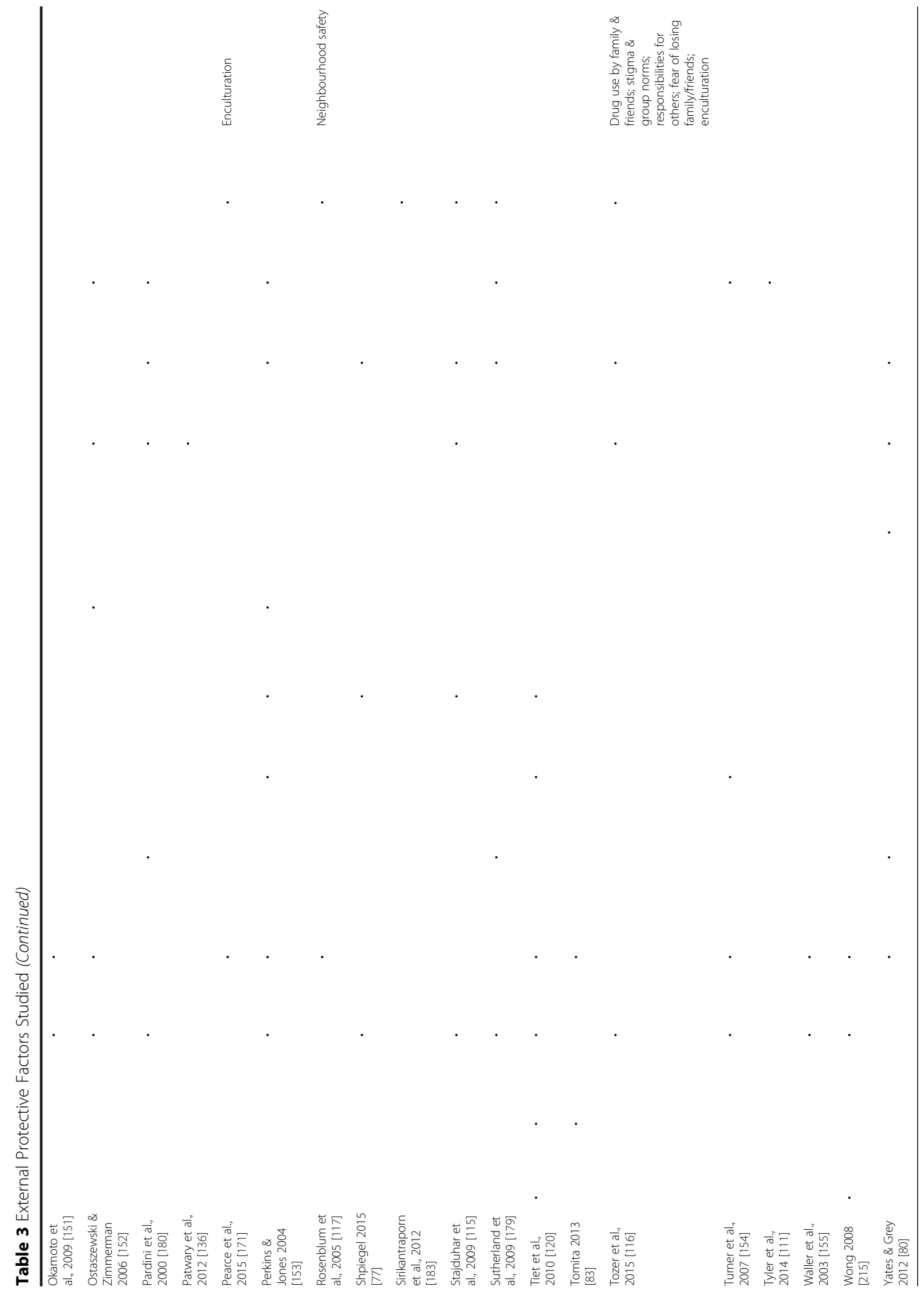


Social support in all its forms (informational, material, and emotional) is a key external factor for resilience, found across all three abovementioned broad levels of external protective factors (e.g., [82, 85, 86, 104, 110, 122, 153]). Indeed, social connectedness (e.g., care, trust, attention, and shared time) and interpersonal relationships feature significantly as external protective factors in many of the reviewed studies (e.g., [76, 79, 104, 113, $119,124])$. However, in this literature a significant amount of attention is paid to family-level and schoolbased external protective factors. This is most likely due to the abundance of youth studies.

Environmental and structural protective factors are less commonly invoked in studies of resilience and drug use. For instance, Longman-Mills et al. [109], in their study of university students who had a history of childhood maltreatment, attempt to bring such factors to the forefront by considering the child protection laws in each of the Latin American and Caribbean countries where they carried out their research. However, these structural factors are not considered in the final analyses.

Religiosity is an interesting protective factor as it features in both internal and external domains. Sometimes this factor is considered an indication of individual faith/ spiritual strength (i.e., "how important are religious beliefs to you" ([109], p. 81), versus religion as an external factor which encompasses elements such as devotion rituals and congregation participation (e.g., [79, 130]). Meanwhile, some authors combine internal and external measures such as the importance of spirituality and the level of service attendance, reporting it as one variable (e.g., $[111,126,153,154])$. Similarly, culture is also a protective factor that spans the realm of internal strengths (i.e., cultural values) and external resources (i.e., cultural practices, enculturation) (e.g., $[85,118,143,151])$.

Internal protective factors are a significant focus in many substance use papers. Researchers continue to see resilience as a trait, emphasizing personality aspects or skills that help people to resist drugs. The focus is on changing the individual, rather than changing the resources available, for that individual, to strengthen resilience. This can perpetuate victim-blaming. Inconsistent use of terminology creates added confusion for concept definitions and operationalizations. External resources for resilience are examined to a lesser extent by research studies. Social support is a key factor for resilience that is found across multiple levels of external resources.

\section{Resilience outcomes}

Positive adaptations are generally considered consequences of resilience for individuals facing adversity. The most common conceptualization of resilience in the substance use literature is outcome-based. This is not altogether surprising, as use of this concept remains consistently outcome- focused throughout many other fields as well (e.g., [28, 75, 156]). However, whether trait, outcome, or process-based conceptualizations of resilience, or a mix of these approaches, are used, more often than not, substance use is rendered a maladaptive behaviour, and the ways in which some individuals are able to resist or remain 'resilient' from substance use is a key line of inquiry in the field of addictions.

Many studies in the reviewed works employ a simple approach, where the presence of resilience is judged by one single outcome measure: the absence of substance use or abuse (e.g., [82, 96, 98, 104, 105, 109, 112, 118, 119, 121, 123, 130, 140, 147, 151, 152, 155, 157, 158]). Resilience here is understood as the capacity to avoid or withstand using drugs, and consequently PWUD are depicted as non-resilient, again giving rise to problematic dichotomies. It is interesting that some researchers do not clarify whether they are concerned with the absence of any level of substance 'use', or if the emphasis is more specifically on 'problem' drug use or abuse (e.g., $[71,100])$. Given that among youth some level of drug experimentation is normal during this period of development, and that desistance in drug use often occurs by a natural process of 'ageing out' [159-161], studies that classify drug using youth as lacking resilience are setting a detrimental precedent. Certainly, this is a problem with outcome-based conceptualizations of resilience in general, as they tend to be static in nature and obscure the possibility of individuals developing resilience to certain outcomes over time, or as circumstances change [75, 137].

Meanwhile, other studies use a multi-dimensional approach to investigate the consequences of resilience, focusing on the presence of several pre-determined positive adaptation measures and/or the absence of negative adjustments (Table 4). Often substance use is examined alongside various other anti-social conduct measures that need to be avoided to provide evidence of resilience: alcohol and cigarette use, mental health problems, risky sexual activity, homelessness, aggression/violence, delinquency/criminal involvement, and conduct problems (school) or rule breaking. In terms of pre-determined positive adaptations, researchers commonly consider: educational attainment, employment, marriage, good interpersonal relations and social skills, good health, and psychosocial functioning. Many of these positive adaptations are biased (i.e., white, middle class) in that these "traditional markers of functionality" ([80], p. 488) often exclude or do not adequately capture resilience experiences for marginalized populations [162, 163].

By expanding their view of potential outcomes, researchers are able to acknowledge that the concept of resilience is multi-dimensional in nature, in that an individual who struggles in one domain can simultaneously possess strengths in another/others [24]. Using such an 


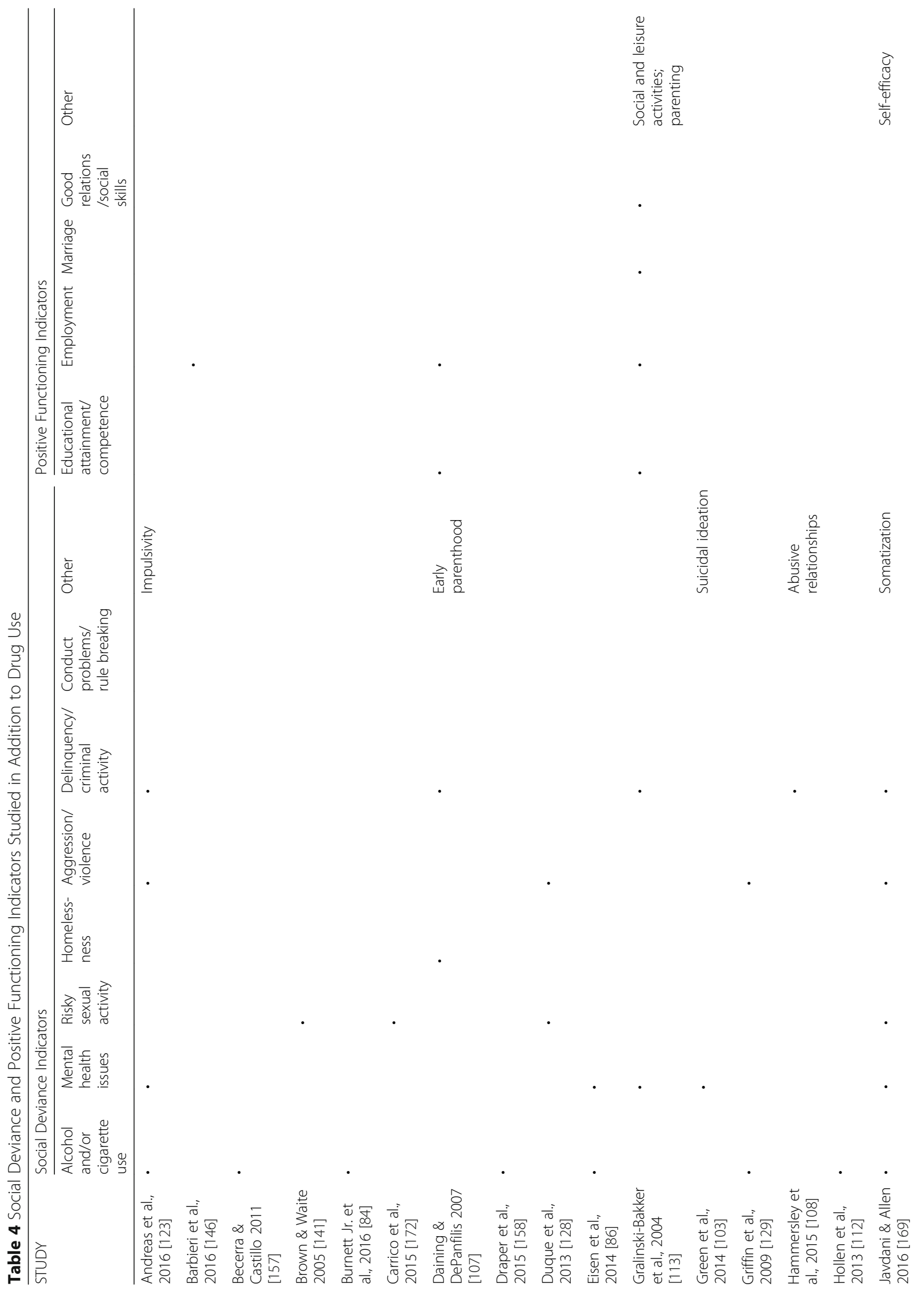




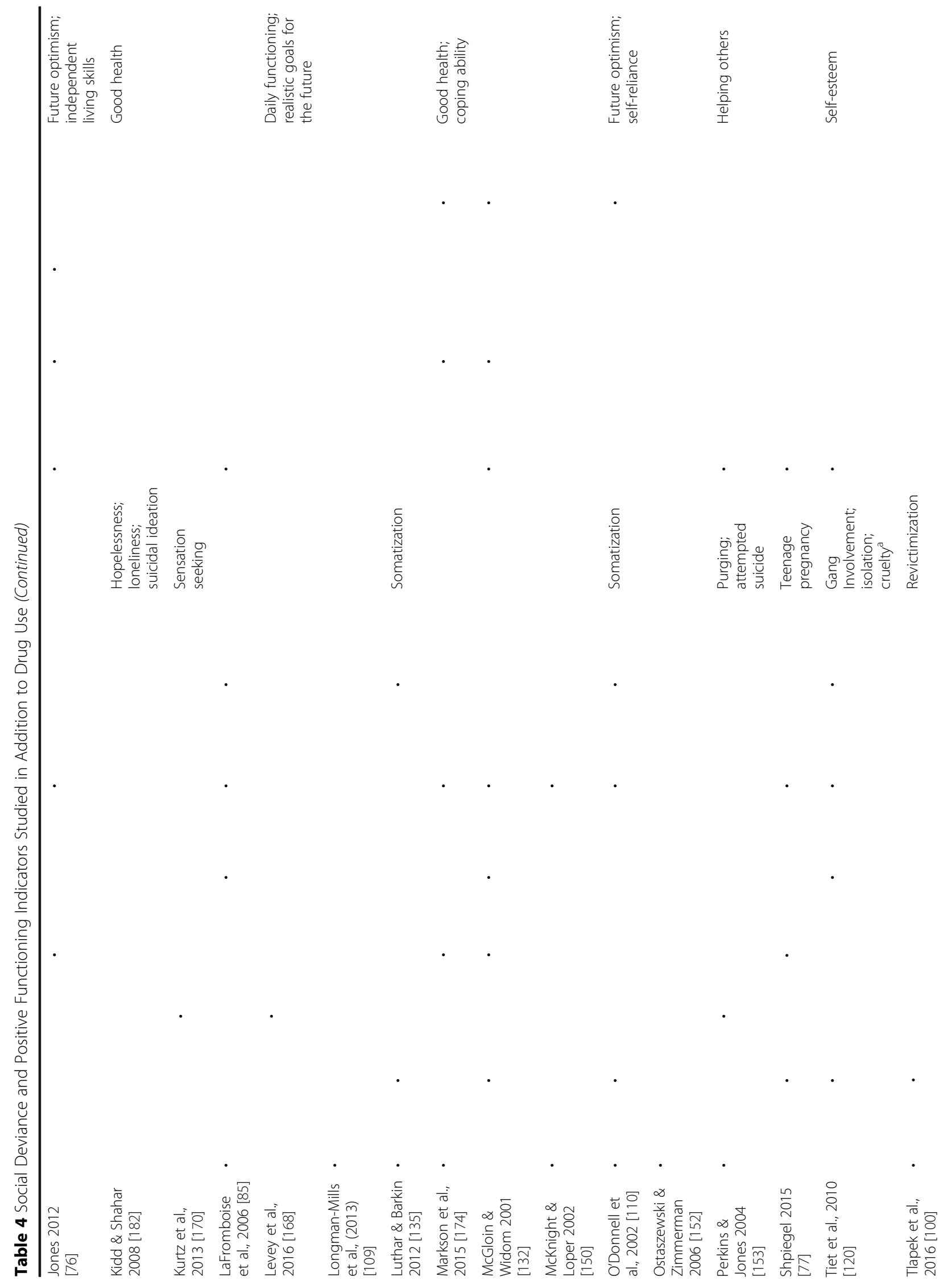


Rudzinski et al. Substance Abuse Treatment, Prevention, and Policy (2017) 12:41

Page 25 of 35

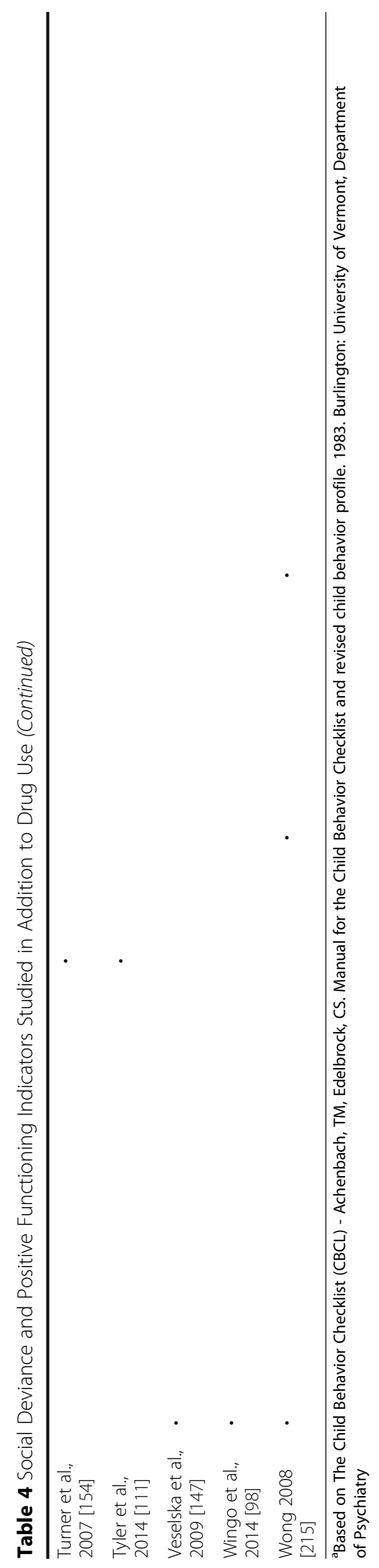


approach is less likely to lead to problematic dichotomies common with single-domain resilience measures. In fact, some researchers are able to move beyond the extremes of resilient vs. non-resilient categories and instead apply multi-level classifications. As a case in point, Daining \& DePanfilis [107] who studied foster youth transitioning into adulthood, consider resilience as the result of a composite score (from 0 to 12) across six domains of functioning (i.e., presence of educational and employment participation, as well as avoidance of early parenthood, homelessness, drug use and criminal activity), allowing for low, medium, and high resilience classifications among participants. Alternately, McGloin \& Widom [132], in their study of abused and neglected children grown up, examine eight functionality domains (i.e., employment, education, and social activity attainment, in addition to absence of psychiatric disorder, homelessness, substance abuse, criminal arrest and violence), and consider a score of 6 out of 8 to demonstrate resilience. These examples reveal that even among studies which investigate several domains of functioning some, like the latter example, will continue resorting to binary categorizations of resilient vs. non-resilient, while others, like the former, allow for a potentially more inclusive operationalization, recognizing the existence of some level of resilience in each category.

Markedly with multi-domain approaches to resilience, some studies allow for low-levels of anti-social behaviour, including drug use. For instance, low level drug use results in lower scores for that domain, but leaves the potential open for better scores in other domains (e.g., [76, 77, 107, 120]). Some investigators recognize the importance of examining both internal and external realms of functioning, seeing the potential for an individual to be internally resilient (e.g., have high levels of psychosocial functioning and self-esteem) and/or externally resilient (e.g., perform well academically, sustain employment and avoid drug use, gang involvement and delinquent activities) (e.g., $[80,120])$. However, there is some debate about whether internal and external resilience should be recognized independently, or whether only those individuals who possess both internal and external adaptation should exclusively be considered resilient [164-166].

In the substance use literature outcome-based conceptualizations of resilience are most commonly utilized. Many studies judge the presence of resilience by the absence of substance use or abuse. Some studies use multidimensional approach adjudicating presence of resilience based on several pre-determined positive adaptation measures or on the absence of negative adjustments. Problematically, outcome-based conceptualizations of resilience are often stagnant and can conceal the potential for developing resilience over time, or as conditions change. However looking at resilience from a multi-dimensional perspective holds great promise, especially if the domains are selected in the context of what is socially and culturally relevant for the population under investigation.

\section{Process-based conceptualizations of resilience}

Braverman ([167], p. 4) argues that "[resilience] researchers have thus far been more successful in identifying protective factors than in explaining how they operate". This definitely rings true in the substance use literature, where significantly fewer researchers attempt to conceptualize resilience as a dynamic process, which explores the interactions between risk and protective factors, than those who utilize an outcome or trait-based approach to operationalize resilience $[79,86,87,102,108,110,113$, $115,120,124,129,151,152,154,155,168-172]$. Just under half of these papers are qualitative investigations of resilience, while the rest are quantitative, utilizing resilience models and longitudinal data sets.

In a qualitative study of adult women trauma survivors in low-income housing, Bowland ([79], p. 2) considers resilience as a dynamic process, and cites an open definition of the concept: resilience is "the process of effectively negotiating, adapting to, or managing significant sources of stress or trauma". By investigating resilience in context, taking into account the individuals, their lives and the constraints of their environment, this researcher is able to effectively analyze practices of resilience for her study population. Indeed, Bowland considers both instances of isolation and experiences of community engagement to be examples of resilience in the midst of adversity. Such a fluid approach to resilience can be quite useful for examining this concept in vulnerable populations.

The fundamental focus in qualitative studies on how risk and protective factors interact with one another, allows for appreciating the dual nature of some of these factors, i.e., seeing how they act protectively in some circumstances and as risks in others. Okamoto and colleagues [151] find that in some cases, both risk and protection occurs because of the close knit family networks of Hawaiian youth. For example, certain family members can protect individuals from drug offers, while it is particularly those close familial bonds that make it hard to refuse drug use in other instances.

When considering substance use and resilience among populations of inner-city/urban adolescents, surveyed longitudinally, both Ostaszewski \& Zimmerman [152] and Tiet et al. [120] utilize dynamic models. Using their data, Ostaszewski \& Zimmerman [152] test the compensatory and risk-protective models of resilience, finding support for the former model and discovering that processes of resilience may operate more effectively at high levels of risk. This study also acknowledges the important cumulative effects of protective factors. 
Tiet et al. [120], on the other hand, develop their own conceptual models which assess interactions of risk and protective factors, helping the authors predict changes in resilience over time. This study provides another prime example of how factors can have a dual nature. In the models tested by Tiet and colleagues [120], over time self-esteem is positively correlated with better adjustment, predicting good psychosocial functioning and academic achievement. Yet, self-esteem is also found to predict higher levels of anti-social behaviour (e.g., drug use, gang involvement). Tiet and his fellow researchers muse that perhaps it takes a certain level of self-esteem for youth to have the courage and charisma to engage in deviant activities and be accepted by delinquent peers.

Although a number of researchers support processbased definitions of resilience, many studies, nevertheless, produce static and outcome-focused conceptualizations of resilience (e.g., [85, 128, 132]). However, several researchers stress the necessity to conceptualize resilience as a process in future studies and advocate for future longitudinal research in order to "capture constructs over time", examining specific interactions between risks, protective factors, resilience, and drug use (e.g., [80, 107, 167]). Yet it must be emphasized that not all longitudinal studies automatically consider resilience as a process (e.g., [173, 174]). Benda [173], in his longitudinal study of homeless veterans who abuse substances measures resilience at only one point in time. Thus, the investigator is unable to provide any information on the changes in resilience over the lives of the study participants.

Fewer studies use a process-based approach to investigate resilience. This dynamic approach to resilience research often uses open-ended definitions which can be quite useful for examining resilience in vulnerable populations. Looking at interactions between risk and protective factors allows us to appreciate the dual nature of these factors, acting protectively in some circumstances and as risks in others. Although a number of researchers support process-based definitions of resilience, many studies, nevertheless, produce static and outcomefocused conceptualizations.

\section{Recovery as resilience}

There is a debate in resilience research about the proper definition of this concept, with many researchers, especially those within the substance use literature, choosing to restrict resilience to individuals who never give in to risks or exhibit maladaptive behaviours (e.g., substance use, addiction) [137, 175]. Meanwhile, there are a smaller number of researchers who hold a wider view of resilience, considering recovery as a distinct example of this concept in action $[115,176,177]$. Thus, when drug- using groups are looked at with respect to resilience, the predominant trend is to look at PWUD in recovery or treatment (Table 1). In fact, many studies focus on aspects such as the process of natural recovery, inner strength, or substance use interventions/treatments, leaving out any notion of the resilience involved in persevering in one's daily life with an ongoing addiction. A special issue on resilience in the journal Substance Use $\mathcal{E}$ Misuse is devoted primarily to examining recovery or the development of children with alcoholic or drug using parents [178].

Definitions of resilience in papers on recovery commonly focus on 'bouncing back' from adversity, with addiction considered the most prominent form of adversity $[126,143,148,179]$. Drug use is often portrayed as a maladaptive coping strategy, and resilience is defined as being able to stay on the path toward recovery from addiction [142, 179]. Maintaining long-term sobriety is considered a positive outcome in these studies [102, 148, 180]. Harris et al. [142], in their Process Model of Addiction and Recovery, stress the idea of 'resilience to relapse' by stating that the 'compulsive cycle of substance dependence' shows a lack of resilience, while the 'coping cycle of recovery' demonstrates resilience in action.

A few of studies comparing resilience between intreatment/recovery/institutionalized PWUD and 'healthy' non-users were also found. These studies consider drug abuse as a maladaptive coping strategy and the majority use scales to measure resilience, finding that addicted individuals consistently score lower on these instruments [99, 179]. Dufour and Nadeau [149] underscore the antithesis between resilience and addiction, while investigating mental health among women who had been sexually abused during childhood. From the outset these researchers designate one group as 'resilient' and the other as 'addicted', failing to consider any evidence of resilience among the in-treatment women. This is especially surprising given the authors' comments that the 'addicted' women are interviewed at the beginning of recovery, "at a moment where they have chosen to help themselves in getting treatment, at a time when they felt a bit more in control of their destiny" ([149], p. 667).

Such restrictive dichotomies are prevalent throughout this area of research (e.g., [108, 148]). Dell et al. [143] argue for the need to reconsider defining individuals who return to active substance use as treatment 'failures' with respect to resilience. Yet, this continues to be the underlying assumption, partly due to the over emphasis on individual-level protective factors, (e.g., readiness to change, motivation, determination, hardiness, psychological strength, spirituality, and optimism), often featured in recovery research $[102,114,142,148,172,179$, 180]. It seems that in some ways resilience is co-opted as yet another trait that helps people recover, and 
differentiates those individuals from persons who continue to use drugs.

The key to a more holistic and contextualized approach to resilience research may be to provide equal attention to external protective factors (e.g., social support, family assistance, community programs, enculturation), and consider the mechanisms and interactions between the individual and their potential resources through which resilience can be built/maintained [108, 143, 146]. In fact, resilience-based recovery programs and interventions, focusing on both internal strengths (e.g., confidence, inner spirit, pride, creativity, developing new skills) and external resources (e.g., community supports, social interaction, cultural participation, aftercare), are currently being developed and evaluated [102, 143, 170, 172, 181].

When resilience is researched among PWUD the predominant trend is to examine individuals in recovery or treatment. Under these circumstances drug use is usually considered a maladaptive coping strategy, and resilience is identified as maintaining long-term sobriety. Individuals who relapse back into active substance use are deemed as 'failures' with respect to resilience, partly due to the over emphasis of individual-level protective factors. Resilience is often designated as a trait that differentiates recovering individuals from persons who actively use drugs.

\section{PWUD and resilience}

In this scoping review of substance use literature, only a small number of studies were found that fully invoked the concept of resilience to examine behaviours of individuals who currently use drugs (Table 1). Several resilience studies discussed current drug use among homeless youth (e.g., [78, 101, 111, 136, 168, 182]), however most had no clear indication of how many study participants were actively using. Moreover, the focus of these studies remains on dealing with the adversity of the street, and/ or on revealing which protective factors are associated with a reduction or cessation of drug use, as well as a number of other social deviance indicators (e.g., criminal involvement, prostitution, suicidal ideation). Drug use is typically portrayed as a habit that needs to be supported, a risk factor for individuals on the street, or a maladaptive coping strategy at odds with resilience.

In this section, the focus of the analyses will be restricted to studies which clearly state that a majority (>60\%) of participants are PWUD. Among these studies there is a shift from regarding 'any' drug use as a negative outcome, to only regarding 'problem' drug use (e.g., dependence, heavy use, drug use before/during sex) in this manner $[116,118,170]$. This type of approach broadens who can be considered resilient, from nonusers to PWUD who are not high-risk. For instance, Tozer and colleagues [116] investigate elements associated with the prevention of transitioning to injection drug use among street-involved youth. In this study, youth who avoid transition to injection are deemed resilient, thus positioning injection drug use specifically, rather than drug use generally, as the negative outcome under consideration.

This scoping review found only five studies that specifically recruited PWUD and utilized the concept of resilience $[87,115,122,171,183]$. Two of these studies use scales to measure resilience, with both trying to moderate the drawbacks of these standard instruments, which are often not able to capture significant aspects associated with resilience for marginalized populations. Buttram et al. [122] in their study of substance-using sex workers utilizes a proxy measure of resilience, selfmastery, yet also measures external factors (i.e., health insurance, transportation access, and social support) in trying to discern what reduces syndemic risk factors (including drug use) for this population. Meanwhile, Pearce and colleagues [171] utilize the CD-RISC to measure resilience, in a study that examines risk and protective factors associated with resilience among a cohort of young Aboriginal peoples who use illicit drugs. However, to strengthen the subjective dimensions of their resilience research, these researchers add elements of cultural connectedness and traditional language, allowing them to see other protective resources for their population. In this study resilience is postulated as resistance to detrimental health outcomes, specifically HCV and HIV, and drug use is considered a risk factor for these health outcomes, yet it is one among many risk factors.

The remaining three studies in this section examine resilience among people who inject drugs (PWID). Generally these studies concentrate on health-related behaviours and harm reduction strategies as evidence of resilience. For example, Stajduhar et al. ([115], p. 310) attempt to reconceptualise resilience for a population of PWID by providing a 'wider' definition: "resilience includes successful adaptation following a period of maladaptation or developmental difficulty. Indeed, it encompasses not only recovery but includes harm reduction practices". However, evidence of resilience, is researcher-defined and remains recovery-related (i.e., quitting or decreasing use), with secondary emphasis on harm reduction strategies (i.e., support seeking or safer use). Moreover, continued drug use as a coping strategy, for these researchers, is considered suppressed resilience. Likewise, Sirikantraporn et al. [183], focus entirely on researcher predefined harm reduction behaviours, such as 'planning to ensure steady access to clean injection equipment', as evidence of resilience among PWID. Although both of these studies point to the unexplored potential of resilience research among PWID and to the power of using this approach to uncover strengths and 'safer' drug use practices that promote well-being, the present 
conceptualizations remain too narrow to see all the potential manifestations of resilience.

Despite these continuously restricted conceptualizations of resilience, researchers who examine this concept among PWUD are able to show that many protective factors identified in the resilience literature for other populations can also be found for individuals who currently use drugs (Tables 2 and 3). Moreover, a few researchers are able to demonstrate that a lot of what would be deemed risk factors can actually have desired outcomes, in terms of resilience, for these vulnerable populations $[115,116]$. For instance, Tozer et al. [116] highlight several untraditional protective factors for young noninjectors, including how the presence of adult injectors or injection by family members, two factors often considered risky, can provide protection in cases when adult injectors discourage injection or when youth see the consequences of injection for family members. By considering the social context of protective factors these researchers are able to emphasize varying sources of support and constraints in the lives of their study participants.

In a novel approach to operationalizing resilience among PWID, Brothers ([87], p. 2) in her study of secondary syringe exchangers (SSEs) relies on an open definition of resilience as "the process of harnessing key resources to sustain well-being". Building on from this Brothers recognizes 'the syringe' as the resource being utilized by SSEs, through their practices of collecting used syringes, exchanging them at harm reduction agencies for new syringes, and distributing clean syringes to other PWID. These acts of exchange in the context of a risk environment are considered by Brothers as examples of resilience in practice, as SSEs work to improve their financial and mental wellbeing. This approach to resilience among PWUD supports the important notion that these individuals are active agents who have significant strengths and capabilities that should be recognized as manifestations of resilience.

Very few studies were found that thoroughly investigated resilience among PWUD. These studies predominantly concentrate on health-related behaviours, recoveryrelated factors or pre-defined harm reduction strategies. Drug use is still often considered a negative outcome or risk factor; however some studies attempt to differentiate between 'any' drug use and 'problem' drug use. Although these studies endeavour to broaden the concept of resilience for PWUD, providing important information regarding protective factors for these individuals, nevertheless overall these conceptualizations are still too limited to recognize all the potentially hidden forms of resilience in the daily lives of individuals who actively use drugs.

\section{Conclusions}

The most common operationalizations of resilience in substance use literature are outcome-based, focusing on the presence of positive adaptations (e.g., abstinence, recovery) or absence of negative outcomes (e.g., drug use, relapse). However this scoping review reveals that there are ongoing difficulties in the utilization of the concept of resilience in this field. Confusion in operationalization and lack of clarity around whether resilience is being treated as a trait, outcome or process (e.g., definitions do not align with conceptualization; reliance on scales overfocused on individual-level factors) as well as issues with inconsistent use of terminology (e.g., resilience vs. resiliency; protective vs. resilience factors) have resulted in a field of study where it is difficult to compare, contrast, and build upon current research. Researchers who do not articulate what they mean by adversity, protective and risk factors, and positive outcomes further add to the semantic ambiguity.

Currently, substance use research provides a substantial amount of information about the internal strengths that can assist in resisting future drug use; however there is less information about the external resources that play a role, especially for adults. Though popular, outcome-based conceptualizations of resilience are often static, concealing the potential for developing resilience over time. Indeed using a dynamic process-based approach, which relies on open-ended definitions or looks at changes in resilience over time, can provide a more useful method for examining resilience in vulnerable populations. At present, when resilience is studied among PWUD the predominant trend is to examine individuals in recovery/treatment. In the few instances when resilience is investigated among persons who are currently actively using drugs the focus remains on health-related behaviours, cessation-related factors (quitting or decreasing use) or predefined harm reduction strategies. Although such progress is encouraging, the present uses of the concept of resilience still disregards resilience practices involved in persevering in one's daily life with an ongoing addiction.

The concept of resilience, as it is currently utilized, is too restrictive and, in essence, leaves drug using individuals out of the realm of investigation [162, 184], leading to a dearth of studies on resilience among PWUD. Consistently throughout the literature, substance use is presented as the antithesis of resilience: drug use is seen as a 'maladaptive coping strategy', purporting one's lack of resilience, or drug use is presented as a 'risk factor' jeopardizing one's ability to be resilient. Problematically many studies fixate on individual-level assets as markers of resilience, most commonly relying on scales and failing to consider wider environmental resources [92, 95]. However, resilience scales, which are often created for white, middle class populations, may not capture features significant for more marginalized groups, resulting in consistently lower scores for PWUD [99, 179]. Similar 
issues have historically been raised with IQ scales and quality of life measures (e.g., [185-190]). This restricted view of resilience is not surprising given the presiding prohibitionist culture where drug use is prohibited, PWUD are punished, and abstinence is considered the best policy [191]. The strength of these underlying ideas is apparent, when considering the public and political controversy caused by harm reduction initiatives in Canada in recent years (e.g., distribution of safer crack use kits, operation of safe consumption sites) [192-196]. Thus, it is no wonder that it is so hard for academics, and the general public alike, to accept that PWUD have the potential for resilience, at least while their use is ongoing.

It is clear from the current use of resilience in studies of PWUD that researchers have only begun to carve out the necessary room for inclusion. Most studies focus on recovery as a form of resilience, which although a step in the right direction, has definite drawbacks as well. The road to recovery is incredibly difficult and often fraught with adversities, thus the value of shedding light on the resilience of individuals who work towards this goal is indispensable. However, what must be reiterated is that recovery should not be considered the sole form of resilience available for PWUD. The problem lies in the fact that recovery from addiction is adjudicated on separate and highly moral grounds. For instance, the recovery model for mental health problems considers success as attaining an "improved quality of life within the limitations caused by the presence of illness" ([181], p. 233), whereas success for addiction recovery is measured by a significant reduction, if not a total abstinence from drug use [197]. Since recovery is typically synonymous with abstinence from drug use, acknowledging this as the only practice of resilience open to PWUD essentially corroborates the limited view that resilience is the absence of drug use, espousing a viewpoint that already dominates in this literature. However, the literature on recovery from addiction accepts the view of "recovery as a process", which involves growth, set back, and fluctuations [198-200], thus it may be open to regarding resilience as modifiable, allowing for process-based conceptualizations for this phenomenon.

Part of the issue with the lack of resilience studies among PWUD is that this concept is difficult to define and operationalize for this ostracized population. Often what is needed to 'do well' or 'get by 'in a drug environment (e.g., tough persona, street knowledge, druginvolved social network contacts) is not considered valuable in other contexts (e.g., school, workplace). Fergus and Zimmerman (2005) argue that resilience processes can include a 'lack of dysfunctional' outcomes; however, it is telling that most studies in the substance use literature focus on this absence of 'negative' outcomes which does not automatically indicate the presence of 'positive', fulfilling lives among participants [69, 201]. Consistently associating drug use with other socially unacceptable consequences leads to this behaviour being regularly interpreted as a risk factor, and omits the reality that many individuals use drugs for various self-perceived benefits in the context of their daily lives [70]. A contextualized approach to analyzing resilience that addresses internal assets, skills and capacities, especially as perceived by the individuals themselves, as well as considers currently accessible resources and external dynamics in the family, community and structural environment (e.g., group supports, social policies), is crucial for recognizing potentially 'hidden' forms of resilience among marginalized populations [32, 163, 202].

In spite of the current difficulties, this scoping review recognizes several important strengths of utilizing the concept of resilience for studying substance use. Firstly, a multi-dimensional conceptualization of resilience creates a more inclusive approach, and in some studies allows for low levels of drug use, without immediately categorizing PWUD as non-resilient. This is a crucial step to seeing resilience among PWUD. However, what is missing is an in-depth evaluation of which other dimensions, beyond typical normative functionality assessments (e.g., academic success, employment), marginalized populations can identify with. A more open-ended definition of resilience, found in several qualitative studies (e.g., [79, 87]), allows for precisely such an investigation. Additionally, these studies show that, such an unstructured approach to resilience research makes it possible to uncover unique responses and adaptations, which can signify resilience in a given context. Finally, process-based conceptualizations of resilience are beneficial in that they concentrate on the manifestations of resilience, that is on the ways in which individuals display resilience (i.e., how individuals use internal strengths or external resources), rather than focusing on measuring 'levels of resilience' (e.g., scale measures, domain scores), as outcome studies do. This kind of exploration provides a better basis for understanding what is really crucial during times of adversity, in order to increase the potential for resilient outcomes for a particular group.

Within the last decade, parallel research fields (e.g., homelessness, sex work) have begun to recognize the potential resilience has to assist in understanding the practices involved in negotiating adverse circumstances among such marginalized populations (e.g., [203-207]). Likewise, there has been a drive to extend who can be considered resilient in the substance use realm. Researchers looking at PWUD strive to show how potential manifestations of resilience are present. Currently these types of analyses have mainly limited themselves to focusing on health-related outcomes, emphasizing reductions in use, motivations for recovery, and safer use practices. However, 
by engaging the possibility for resilience among individuals who continue to use drugs, these studies provide another significant step to creating the space necessary for furthering resilience research among PWUD.

In fact, the concept of resilience holds incredible potential for research among PWUD. Currently, studies of persons who actively use drugs showcase the possibilities of resilience research and the power of using this line of inquiry to examine unexplored strengths and 'safer' drug use practices that promote well-being for PWUD [115, 183]. Although conventional conceptualizations of resilience are strained when applied to the study of marginalized populations, this can motivate researchers to engage a "more contextually sensitive understanding of resilience", which takes into account environmental constraints, available resources, and the values and goals of individuals under investigation [32, 79, 87, 101]. Such an approach provides us with a "corrective lens" when analyzing seemingly 'anti-social' practices of PWUD, or other vulnerable populations, allowing for a deeper awareness of how these behaviours are appropriate expressions of resilience in the given context [101, 208, 209]. Indeed, the concept of resilience, despite its many complexities, gives investigators a platform from which to highlight hidden, socially marginalized, misunderstood, or de-valued practices indicative of resilience, and to explore the unique ways in which individuals appraise, adapt to, and cope with different forms of adversity in a variety of social and cultural contexts [184, 210].

Resilience research among active drug using populations has the potential to dispel some of the myths and negative stereotypes regarding PWUD. Returning to our introductory example of crack smoking; currently there persists a particularly negative discourse around crack use and people who use crack. In fact, perhaps more so than any other addict, the crack user has been 'vilified and ostracized' in both popular culture and academic research $[37,211,212]$. By shifting focus to the strengths and capacities of individuals who use crack, this kind of research can promote a view of these individuals as capable, resourceful, motivated persons who persevere amidst difficult circumstances. Research among individuals who use crack can lend credibility to the resilience practices that these individuals engage in by documenting them as well as using the information gained to advocate on behalf of this population. Such research is also crucial for creating new policies, programs, and interventions that can benefit PWUD.

\footnotetext{
Abbreviations

CD-RISC: Connor-Davidson Resilience Scale; HCV: hepatits C virus; HIV: human immunodeficiency virus; IQ: intelligence quotient; PWID: people who inject drugs; PWUD: people who use drugs; RS: Wagnild \& Young Resilience Scale; SSEs: secondary syringe exchangers
}

Acknowledgements

Not applicable

\section{Funding}

KR would like to acknowledge funding support from a Doctoral Research Award from Social Sciences and Humanities Research Council of Canada (SSHRC), the Queen Elizabeth II/C.P. Shah Scholarship in Science and Technology (QEIIGSST), and the Dalla Lana School of Public Health, University of Toronto.

\section{Availability of data and materials}

All data generated or analysed during this study are included in this published article.

\section{Authors' contributions}

KR wrote the manuscript with contributions from PM, RG, and CS. KR and CS conceptualized the study. KR analyzed the data. PM, RG, and CS provided critical review. All authors read and approved the manuscript.

Ethics approval and consent to participate

Not applicable

\section{Consent for publication}

Not applicable

\section{Competing interests}

The authors declare that they have no competing interests.

\section{Publisher's Note}

Springer Nature remains neutral with regard to jurisdictional claims in published maps and institutional affiliations.

\section{Author details}

${ }^{1}$ Dalla Lana School of Public Health, University of Toronto, 155 College St, Toronto, ON M5T 3M7, Canada. ${ }^{2}$ Centre for Criminology \& Sociolegal Studies, University of Toronto, 14 Queen's Park Crescent West, Toronto, ON M5S 3K9, Canada.

Received: 24 March 2017 Accepted: 28 August 2017

Published online: 15 September 2017

\section{References}

1. McDermott $\mathrm{E}, \mathrm{Graham} H$. Resilient young mothering: social inequalities, late modernity and the 'problem' of 'teenage' motherhood. J Youth Stud. 2005; 8:59-79.

2. Falck RS, Wang J, Siegal HA, Carlson RG. The prevalence of psychiatric disorder among a community sample of crack cocaine users: an exploratory study with practical implications. J Nerv Ment Dis. 2004;192:503-7.

3. Bennett T, Holloway K, Farrington D. The statistical association between drug misuse and crime: a meta-analysis. Aggress Violent Behav. 2008;13:107-18.

4. Bourgois P. In search of respect: selling crack in el barrio. New York: Cambridge University Press; 1995.

5. Cross JC, Johnson BD, Rees Davis W, James Liberty H. Supporting the habit: income generation activities of frequent crack users compared with frequent users of other hard drugs. Drug Alcohol Depend. 2001;64:191-201.

6. Inciardi JA. Crack, crack house sex, and HIV risk. Arch Sex Behav. 1995;24:249.

7. Logan TK, Leukefeld C. Sexual and drug use behaviors among female crack users: a multi-site sample. Drug Alcohol Depend. 2000;58:237-45.

8. Maher L, Dunlap E, Johnson B, Hamid A. Gender, power and alternative living arrangements in the inner-city crack culture. J Res Crime Delinq. 1996;33:181-205.

9. Roy É, Haley N, Leclerc P, Boivin J-FF, Cedras L, Vincelette J. risk factors for hepatitis C virus infection among street youths. CMAJ. 2001;165:557-60.

10. Shannon K, Rusch M, Morgan R, Oleson M, Kerr T, Tyndall MW. HIV and HCV prevalence and gender-specific risk profiles of crack cociane smokers and dual users of injection drugs. Subst Use Misuse. 2008;43:521-34.

11. Sharpe $\Pi$. Behind the eight ball: sex for crack cocaine exchange and poor black women. New York: Haworth Press; 2005.

12. Boyle K, Anglin M. "to the curb": sex bartering and drug use among homeless crack users in Los Angeles. In: Ratner M, editor. Crack pipe as pimp: an ethnographic investigation of sex-for-crack exchanges. New York: Lexington Books; 1993. p. 159-86.

13. Feldman HW, Espada F, Penn S, Byrd S. Street status and the sex-for-crack scene in San Francisco. In: Ratner M, editor. Crack pipe as pimp: an ethnographic investigation of sex-for-crack exchanges. New York: Lexington Books; 1993. p. 133-58. 
14. Falck RS, Wang J, Carlson RG, Siegal HA. The epidemiology of physical attack and rape among crack-using women. Violence Vict. 2001;16:79-89.

15. McElrath K, Chitwood DD, Comerford M. Crime victimization among injection drug users. J Drug Issues. 1997;27:771-83.

16. Neale J, Robertson M. Recent cocaine and crack use among new drug treatment clients in Scotland. Drugs (Abingdon Engl). 2004;11:79-90.

17. Sales P, Murphy S. Survivng violence: pregnancy and drug use. J Drug Issues. 2000;30:695-724.

18. Mugford S. Social change and the control of psychotropic drugs - risk management, harm reduction and 'postmodernity'. Drug Alcohol Rev. 1993;12:369-75.

19. Martins SS, Sampson L, Cerda M, Galea S. Worldwide prevalence and trends in unintentional drug overdose: a systematic review of the literature. Am J Public Health. 2015;105:e29-49.

20. Macdonald S, Anglin-Bodrug K, Mann R, Erickson P, Hathaway A, Chipman $M$, et al. Review: injury risk associated with cannabis and cocaine use. Drug Alcohol Depend. 2003;72:99-115.

21. Rhodes T. Risk theory in epidemic times: sex, drugs, and the social organization of 'risk behaviour. Sociol Health IIIn. 1997;19:208-27.

22. Masten AS, Best KM, Garmezy N. resilience and development: contributions from the study of children who overcome adversity. Dev Psychopathol. 1990;2:425-44

23. Masten AS. Ordinary magic: resilience processes in development. Am Psychol. 2001;56:227-38.

24. Luthar SS, Cicchetti D, Becker B. The construct of resilience: a critical evaluation and guidelines for future work. Child Dev. 2000;71:543-62.

25. Block J, Kremen M. IQ and ego-resiliency: conceptual and empirical connections in separateness. J Pers Soc Psychol. 1996;70:349-61.

26. Jacelon C. The trait of resilience. J Adv Nurs. 1997;25:123-9.

27. Kolar K. Resilience: revisiting the concept and its utility for social research. Int J Ment Health Addict. 2011;9:421-33.

28. Mancini A, Bonanno G. Predictors and parameters of resilience to loss: toward an individual differences model. J Pers. 2009;77:1805-32.

29. Tusaie K, Dyer J. Resilience: a historical review of the construct. Holist Nurs Pract. 2004;18:3-10.

30. Bonanno GA, Romero SA, Klein SI. The temporal elements of psychologica resilience: an integrative framework from the study of individuals, families, and communities. Psychol Inq. 2015;26:139-69.

31. Glantz M, Sloboda Z. Analysis and reconceptualization of resilience. In: Glantz M, Sloboda Z, editors. Resilience and development: positive life adaptations. New York: Kluwer Adacemic/Plenum; 1999. p. 109-26.

32. Ungar M. Nurturing hidden resilience in troubled youth. Toronto: University of Toronto Press; 2004

33. Ungar M. Qualitative contributions to resilience research. Qual Soc Work. 2003:2:85-102.

34. Ungar M. A constructionist discourse on resilience: multiple contexts, multiple realities among at-risk children and youth. Youth Soc. 2004:35:341-65.

35. Maher L. Sexed work: gender, race, and resistance in a Brooklyn drug market. Oxford: Clarendon Press; 1997.

36. Sterk CE. Fast lives: women who use crack cocaine. Philadelphia: Temple University Press; 1999.

37. Copes H, Hochstetler A, Williams JP. "We weren't like no regular dope fiends": negotiating hustler and crackhead identities. Soc Probl. 2008;55:254-70.

38. Erickson PG, Butters J, McGillicuddy P, Hallgren A. Crack and prostitution: gender, myths, and experiences. J Drug Issues. 2000;30:767-88.

39. Kearney $\mathrm{MH}$, Murphy S, Rosenbaum M. Mothering on crack cocaine: a grounded theory analysis. Soc Sci Med. 1994;38:351-61.

40. Ribeiro LA, Sanchez ZM, Nappo SA. Surviving crack: a qualitative study of the strategies and tactics developed by Brazilian users to deal with the risks associated with the drug. BMC Public Health. 2010;10:1-10.

41. Brown EJ, Trujillo TH. "Bottoming out?" among rural African American women who use cocaine. J Rural Health. 2003:19:441-9.

42. Draus PJ, Carlson RG. "The game turns on you": crack, sex, gender, and power in small-town Ohio. J Contemp Ethnogr. 2009:38:384-408.

43. Kirst M. Social capital and beyond: a qualitative analysis of social contextual and structural influences on drug-use related health behaviors. J Drug Issues. 2009;39:653-76.

44. Ratner MS. Crack pipe as pimp: an ethnographic investigation of sex-forcrack exchanges. New York: Lexington Books; 1993.

45. Dalla RL. Exposing the 'pretty woman' myth: a qualitative examination of female streetwalking prostitutes. J Sex Res. 2000;37:344-53.
46. Windsor LC, Dunlap E, Golub A. Challenging controlling images, oppression, poverty, and other structural constraints: survival strategies among AfricanAmerican women in distressed households. J Afr Am Stud (New Brunsw). 2011;15:290-306.

47. Agani F, Landau J, Agani N. Community-building before, during, and after times of trauma: the application of LINC model of community resilience in Kosovo. Am J Orthop. 2010;80:143-9.

48. Kumpfer KL, Whiteside HO, Greene JA, Allern KC. Effective outcomes of four age versions of the strengthening families program in statewide field sites. Group Dyn. 2010;14:211-29.

49. Landau J, Mittal M, Wieling E. Linking human systems: strengthening individuals, families, and communities in the wake of mass trauma. J Marital Fam Ther. 2008:34:193-209.

50. Usher K, Jackson D, O'Brien L. Adolescent drug abuse: helping families survive. Int J Ment Health Nurs. 2005:14:209-14.

51. Arksey H, O'Malley L. Scoping studies: toward a methodological framework. Int J Soc Res Methodol. 2015;8:19-32.

52. Valtonen K, Padmore JC, Sogren M, Rock L. Lived experiences of vulnerability in the childhood of persons recovering from substance abuse. J Soc Work (Lond). 2009;9:39-60.

53. Cepeda A, Saint Onge JM, Kaplan C, Valdez A. The association between disaster-related experiences and mental health outcomes among drug using African American hurricane Katrina evacuees. Community Ment Health J. 2010;46:612-20.

54. Hammersley R. Pathways through drugs and crime: desistance, trauma and resilience. J Crim Justice. 2011;39:268-72.

55. Lim SH, Ostrow D, Stall R, Chmiel J, Herrick A, Shoptaw S, et al. Changes in stimulant drug use over time in the MACS: evidence for resilience against stimulant drug use among men who have sex with men. AIDS Behav. 2012;16:151-8

56. Rosser R, Stevens S, Ruiz B. Cognitive markers of adolescent risk taking: a correlate of drug abuse in at-risk individuals. Prison J. 2005:85:83-96.

57. Lindsey RL, Weist MD, Smith-Lebeau L, Rosner L, Dixon LB, Pruitt DD. Significance of self-reported drug or alcohol use among inner-city teenagers. Psychiatr Serv. 2004;55:824-6.

58. Stanis JJ, Andersen SL. Reducing substance use during adolescence: a translational framework for prevention. Psychopharmacology. 2014;231:1437-53.

59. Becona E, Martinez U, Calafat A, Juan M, Duch M, Fernandez-Hermida JR How does family disorganization influence children's drug use. Adicciones. 2012;24:253-68.

60. Fisher HH, Eke AN, Cance JD, Hawkins SR, Lam WKK. Correlates of HIVrelated risk behaviors in African American adolescents from substance-using families: patterns of adolescent-level factors associated with sexual experience and substance use. J Adolesc Health. 2008;42:161-9.

61. Massey SH, Compton MT, Kaslow NJ. Attachment security and problematic substance use in low-income, suicidal, African American women. Am J Addict. 2014:23:294-9.

62. Pettenon M, Kessler FHP, Guimaraes LSP, Pedroso RS, Hauck S, Pechansky F. Perceptions of parental bonding in freebase cocaine users versus non-illicit drug users. Indian J Med Res. 2014;139:835-40.

63. Daniulaityte R, Carlson RG. "To numb out and start to feel nothing": Expereinces of stress among crack-cocaine using women in a midwestern city. J Drug Issues. 2011:41:1-24.

64. Laudet $A B$, White $W L$. Recovery capital as prospective predictor of sustained recovery, life satisfaction, and stress among former poly-substance users. Subst Use Misuse. 2008;43:27-54

65. Timpson S, Ratliff E, Ross M, Williams M, Atkinson J, Bowen A, et al. A psychosocial comparison of New Orleans and Houston crack smokers in the wake of hurricane Katrina. Subst Use Misuse. 2009:44:1695-710.

66. Brown JH. Youth, drugs and resilience education. J Drug Educ. 2001;31:83-122.

67. Dew B, Ellfson K, Dozier M. Social and environmental factors and their influence on drug use vulnerability and resiliency in rural populations. Rural Health. 2007;23(Suppl 1):16-21.

68. Dillon L, Chivite-Matthews N, Grewal I, Brown R, Webster S, Weddell E et al.. Risk, protective factors and resilience to drug use: identifying resilient young people and learning from their experiences. 2007. London, Research Development and Statistics Directorate, Home Office. Avialable at http:// dera.ioe.ac.uk/8471/1/rdsolr0407.pdf.

69. Fergus S, Zimmerman MA. Adolescent resilience: a framework for understanding healthy development in the face of risk. Annu Rev Public Health. 2005;26:399-419. 
70. Freshman A, Leinwand C. The implications of female risk factors for substance abuse prevention in adolescent girls. J Prev Interv Community. 2000;21:29-51.

71. Maring EF, Malik BB, Wallen J. Drug abuse in India: grounding research in ecological risk and resilience theory. Fam Consum Sci Res J. 2012;41:172-82.

72. Meschke LL, Patterson JM. Resilience as a theoretical basis for substance abuse prevention. J Prim Prev. 2003;23:483-514.

73. Taylor OD. The cultural influence of adolescent prescription drug abuse. J Hum Behav Soc Environ. 2015;25:304-11.

74. Coren E, Hossain R, Pardo Pardo J, Bakker B. Interventions for promoting reintegration and reducing harmful behaviour and lifestyles in streetconnected children and young people (Review). Cochrane Database of Syst Rev. Issue 1. Art. No.: CD009823. pub 3. 2016. doi:10.1002/14651858. CD009823.pub3.

75. Kaplan H. Toward an understanding of resilience: A critical review of definitions and models. In: Glantz M, Johnson J, editors. Resilience and development: Positive life adaptations. New York: Kluwer Academic/Plenum; 1999. p. 17-84.

76. Jones L. Measuring resiliency and its predictors in recently discharged foster youth. Child Adolesc Social Work J. 2012;29:515-33.

77. Shpiegel S. Resilience among older adolescents in foster care: the impact of risk and protective factors. Int J Ment Health Addict. 2015;14:6-22.

78. Hills F, Meyer-Weitz A, Oppongo Asante K. The lived experiences of street children in Durban, South Africa: violence, substance use, and resilience. Int J Qual Stud Health Well-being. 2016;11:30302.

79. Bowland S. Aging in place or being warehoused? African American trauma survivors in mixed-age housing. Traumatology (Tallahass Fla). 2015;21:172-80.

80. Yates TM, Grey IK. Adapting to aging out: profiles of risk and resilience among emancipated foster youth. Dev Psychopathol. 2012;24:475-92.

81. Chang W, Bendel TL, Koopman C, McGarvey EL, Canterbury RJ. Delinquents' safe sex attitudes. Crim Justice Behav. 2003;30:210-29.

82. Davis SJ, Spillman S. Reasons for drug abstention: a study of drug use and resilience. J Psychoactive Drugs. 2011:43:14-9.

83. Tomita M. The resilience of women drug users sentenced to the execution of a custodial sentence. Revista Asistenta Sociala. 2013;12:95-106.

84. Burnett HJ Jr, Witzel K, Allers K, McBride DC. Understanding the relationship of trauma, substance use, and resilience among religiously affiliated university students. J Res Christ Educ. 2016;25:317-34.

85. LaFromboise TD, Hoyt DR, Oliver L, Whitbeck LB. Family, community, and school influences on resilience among American Indian adolescents in the upper midwest. J Community Psychol. 2006;34:193-209.

86. Eisen SV, Schultz MR, Glickman ME, Vogt D, Martin JA, Osei-Bonsu PE, et al. Postdeployment resilience as a predictor of mental health in operation enduring freedom/operation iraqi freedom returnees. Am J Prev Med. 2014:47:754-61.

87. Brothers S. Merchants, samaritans, and public health workers: secondary syringe exchanger discursive practices. Int J Drug Policy. 2016:37:1-8.

88. Connor KM, Davidson JR. Development of a new resilience scale: the Connor-Davidson resilience scale (CD-RISC). Depress Anxiety. 2003;18:76-82.

89. Bartone P. Test-restest reliability of the dispositional resilience scale-15, a brief hardiness scale. Psychol Rep. 2007;101:943-4.

90. Campbell-Sills L, Stein MB. Psychometric analysis and refinement of the Connor-Davidson resilience scale (CD-RISC): validation of a 10-item measure of resilience. J Trauma Stress. 2007;20:1019-28.

91. Sinclair V, Wallston K. The development and psychometric evaluation of the brief resilient coping scale. Assessment. 2004;11:94-101.

92. Smith-Osbourne A, Bolton KW. Assessing resilience: a review of measures across the life-course. J Evid Based Soc Work. 2013;10:111-26.

93. Wagnild GM, Young HM. Development and psychometric evaluation of the resilience scale. J Nurs Meas. 1993;1:165-78.

94. Pearlin L, Menaghan E, Lieberman M, Mullen J. The stress process. J Health Soc Behav. 1981;22:337-56

95. Windle G, Bennett KM, Noyes J. A methodological review of resilience measurement scales. Health Qual Life Outcomes. 2011:9:1-18.

96. Fadardi JS, Azad H, Nemati A. The relationship between resilience, motivational structure, and substance use. Procedia Soc Behav Sci. 2010;5:1956-60.

97. Martin L, Viljoen M, Kidd M, Seedat S. Are childhood trauma exporsures predictive of anxiety sensitivity in school attending youth? J Affect Disord. 2014;168:5-12.

98. Wingo AP, Ressler KJ, Bradley B. Resilience characteristics mitigate tendency for hamrful alcohol and illicit drug use in adults with a history of childhood abuse: a cross-sectional study of 2024 inner-city men and women. Psychiatr Res. 2014;51:93-9.

99. Cuomo C, Sarchiapone M, Di Giannantoni M, Mancini M, Roy A. Aggression, impulsivity, personality traits, and childhood trauma of prisoners with substance abuse and addiction. Am J Drug Alcohol Abuse. 2008;34:339-45.

100. Tlapek SM, Auslander W, Edmond T, Gerke D, Voth Schrag R, Threlfall J. The moderating role of resiliency on the negative effects of childhood abuse for adolescent girls involved in child welfare. Child Youth Serv Rev. 2016;73:437-44.

101. Wachter K, Thompson SJ, Bender K, Ferguson K. Predictors of multiple arrests among homeless young adults: gender differences. Child Youth Serv Rev. 2015;49:32-8.

102. Alavijeh M-M, Matin BK, Jalilian F, Hamzeh B, Haghighi M, Ahmadpanah M, et al. Relapse prevention intervention among Iranian addicts based on theory of planned behaviour results. Res J Appl Sci. 2016;11:138-43.

103. Green KT, Calhoun PS, Dennis MF, Beckham JC. Exploration of the resilience construct in posttraumatic stress disorder severity and functional correlates in military combat veterans who have served since September 11, 2001. J Clin Psychiatry. 2014;71:823-30.

104. Amandru S, Bantu E, Mwebi B, OKwara M, Onderi H. Adolescent resilience, social support and drug abuse a case of Koboko district, West Nile, Uganda. Basic Res J Educ Res Rev. 2014;3:35-44.

105. Hodder RK, Freund M, Bowman J, Wolfenden L, Gillham K, Dray J, et al. Association between adolescent tobacco, alcohol and illicit drug use and individual and environmental resilience protective factors. BMJ Open. 2016;6:11.

106. Almedom A, Glandon D. Resilience is not the absence of PTSD any more than health is the absence of disease. J Loss Trauma. 2007;12:127-43.

107. Daining C, DePanfilis D. Resilience of youth in transition from out-of-home care to adulthood. Child Youth Serv Rev. 2007;29:1158-78.

108. Hammersley R, Dalgarno P, McCollum S, Reid M, Strike Y, Smith A, et al. Trauma in the childhood stories of people who have injected drugs. Addict Res Theory. 2015;24:135-51.

109. Longman-Mills S, Gonzalez WY, Melendez MO, Garcia MR, Gomez JD, Juarez $C G$, et al. Exploring child maltreatment and its relationship to alcohol and cannabis use in selected Latin American and Caribbean countries. Child Abuse Negl. 2013;37:77-85.

110. O'Donnell DA, Schwab-Stone ME, Muyeed AZ. Multidimensional resilience in urban children exposed to community violence. Child Dev. 2002;73:1265-82.

111. Tyler KA, Kort-Butler LA, Swendener A. The effect of victimization, mental health, and protective factors on crime and illicit drug use among homeless young adults. Violence Vict. 2014;29:348-62.

112. Hollen PJ, Tyc VL, Shannon SV, Donnangelo SF, Hobbie WL, Hudson MM, et al. Factors related to decision making and substance use in adolescent survivors of childhood cancer: a presenting clinical profile. J Cancer Surviv. 2013;7:500-10.

113. Gralinski-Bakker JH, Hauser ST, Stott C, Billings RL, Allen JP. Markers of resilience and risk: adult lives in a vulnerable population. Res Hum Dev. 2004;1:291-326.

114. Hopwood M, Treloar C. Resilient coping: applying adaptive responses to prior adversity during treatment for hepatitis C infection. J Health Psychol. 2008;13:17-27.

115. Stajduhar Kl, Funk L, Shaw AL, Bottorff JL, Johnson J. Resilience from the perspective of the illicit injection drug user: an exploratory descriptive study. Int J Drug Policy. 2009;20:309-16.

116. Tozer K, Tzemis D, Amlani A, Coser L, Taylor D, van Borek N, et al. Reorientating risk to resilience: street-involved youth perspectives on preventing the transition to injection drug use. BMC Public Health. 2015;15:1-11.

117. Rosenblum A, Magura S, Fong C, Cleland C, Norwood C, Casella D, et al. Substance use among young adolescents in HIV-affected families: resiliency, peer deviance, and family functioning. Subst Use Misuse. 2005;40:581-603.

118. Currie CL, Wild TC, Schopflocher DP, Laing L, Veugelers P. Illicit and prescription drug problems among urban aboriginal adults in Canada: the role of traditional culture in protection and resilience. Soc Sci Med. 2013;88:1-9.

119. Marsiglia FF, Miles BW, Dustman P, Sills S. Ties that protect: an ecological perspective on Latino/a urban pre-adolescent drug use. J Ethn Cult Divers Soc Work. 2002;11:191-220.

120. Tiet QQ, Huizinga D, Byrnes HF. Predictors of resilience among inner-city youths. J Child Fam Stud. 2010;19:360-78.

121. Gilliard-Matthews S, Stevens R, Medina M. 'If drugs does that to you, then I don't want it.' resiliency among non-marijuana using adolescents. J Youth Stud. 2016;19:1237-58.

122. Buttram ME, Surratt HL, Kurtz SP. Resilience and syndemic risk factors among African-American female sex workers. Psychol Health Med. 2014;19:442-52. 
123. Andreas JB, Pape H, Bretteville-Jensen AL. Who are the adolescents saying "no" to cannabis offers. Drug Alcohol Depend. 2016;163:64-70.

124. Christiansen EJ, Evans WP. Adolescent victimization, testing models of resiliency by gender. J Early Adolesc. 2005;25:298-316.

125. Kassis W, Artz S, Moldenhauer S. Laying down the family burden: a crosscultural analysis of resilience in the midst of family violence. Child Youth Serv. 2013;34:37-63.

126. Benda BB. Discriminators of suicide thoughts and attempts among homeless veterans who abuse substances. Suicide Life Threat Behav. 2003;33:430-42.

127. Bonanno GA. Loss, trauma, and human resilience: have we underestimated the human capacity to thrive after extremely aversive events? Am Psychol. 2004:59:20-8.

128. Duque LF, Montoya NE, Restrepo A. Agressors and resilient youth in Medellin, Colombia: the need for a paradigm shift in order to overcome violence. Cad Saude Publica. 2013:29:2208-16.

129. Griffin JP, Holliday RC, Frazier E, Braithwaite RL. The BRAVE (building resiliency and vocational excellence) program: evaluation findings for a career-oriented substance abuse and violence preventive intervention. J Health Care Poor Underserved. 2009;20:798-816.

130. Moon DG, Jackson KM, Hecht ML. Family risk and resiliency factors, substance use, and the drug resistance process in adolescence. J Drug Educ. 2000;30:373-98.

131. Fletcher D, Sarkar M. Psychological resilience: a review and critique of definitions, concepts, and theory. Eur Psychol. 2013;18:12-23.

132. McGloin JM, Widom CS. Resilience among abused and neglected children grown up. Dev Psychopathol. 2001;13:1021-38.

133. Luthar SS, Cicchetti D. The construct of resileince: implications for interventions and social policies. Dev Psychopathol. 2000;12:857-85.

134. Jackson D, Firtko A, Edenborough M. Personal resilience as a strategy for surviving and thriving in the face of workplace adversity: a literature review. J Adv Nurs. 2007;60:1-9.

135. Luthar SS, Barkin SH. Are affluent youth truly 'at risk'? Vulnerability and resilience across three diverse samples. Dev Psychopathol. 2012;24:429-49.

136. Patwary MA, O'Hare WT, Karim SA, Sarker MH. the motivations of young people moving into medical waste scavenging as a street career. J Youth Stud. 2012;15:591-604.

137. Rutter M. Resilience: Some conceptual considerations. J Adolesc Health. 1993;14:626-31.

138. Rutter M. Resilience in the face of adversity: protective factors and resistance to psychiatric disorders. Br J Psychiatry. 1985;147:598-611.

139. Burke P. Enhancing hope and resilience through a spiritually sensitive focus in the treatment of trauma and addiction. J Chem Depend Treat. 2006;8: 187-206.

140. Brents LK, Tripathi SP, Young J, James A, Kilts CD. The role of childhood maltreatment in the altered trait and global expression of personality in cocaine addiction. J Psychiatr Res. 2015;64:23-31.

141. Brown EJ, Waite CD. Perceptions of risk and resiliency factors associated with rural African American adolescents substance abuse and HIV behaviors. J Am Psychiatr Nurses Assoc. 2005;11:88-100.

142. Harris KJ, Smock SA, Wilkes MT. Relapse resilience: a process model of addiction and recovery. J Fam Psychother. 2011;22:265-74.

143. Dell C, Dell DE, Hopkins C. Resiliency and holistic inhalant abuse treatment. J Aborig Health. 2005;2:4-13.

144. Waller MA. Resilience in the ecosystemic context: evolution of the concept. Am J Orthop. 2001;71:290-7.

145. Kirmayer LJ, Sehdev M, Whitley R, Dandeneau SF, Isaac C. Community resilience: models, metaphors and measures. J Aborig Health. 2009;5:62-117.

146. Barbieri B, Dal Corso L, Di Sipio AM, De Carlo A. Small opportunities are often the beginning of great enterprises: the role of work engagement in support of people through the recovery process and in preventing relapse in drug and alcohol abuse. Work. 2016;55:373-83.

147. Veselska Z, Geckova AM, Orosova O, Gajdosova B, van Dijk JP, Reijneveld SA. Self-esteem and resilience: the connection with risky behavior among adolescents. Addict Behav. 2009:34:287-91.

148. Bradshaw SD, Shumway ST, Harris KS, Baker AK. Predicitive factors of readiness for change during inpatient treatment. Alcohol Treat Q. 2013;31:280-302.

149. Dufour MH, Nadeau L. Sexual abuse: a comparison between resilient victims and drug-addicted victims. Violence Vict. 2001;16:655-72.

150. McKnight LR, Loper $A B$. The effect of risk and resilience factors on the prediction of delinquency in adolescent girls. Sch Psychol Int. 2002;23:186-98
151. Okamoto SK, Helm S, Po'Akekuawela K, Chin ClH, Nebre LRH. Community risk and resiliency factors related to drug use of rural native Hawaiian youth: an exploratory study. J Ethn Subst Abus. 2009;8:163-77.

152. Ostaszewski K, Zimmerman MA. The effects of cumulative risks and promotive factors on urban adolescent alcohol and other drug use: a longitudinal study of resiliency. Am J Community Psychol. 2006;38:237-49.

153. Perkins DF, Jones KR. Risk behaviors and resiliency within physically abused adolescents. Child Abuse Negl. 2004;28:547-63.

154. Turner MG, Hartman JL, Exum ML, Cullen FT. Examining the cumulative effects of protective factors: resiliency among a national sample of high-risk youths. J Offender Rehabil. 2007;46:81-111.

155. Waller MA, Okamoto SK, Miles BW, Hurdle DE. Resiliency factors related to substance use/resistance: perceptions of native adolescents of the southwest. J Sociol Soc Welf. 2003;30:79-94.

156. Olsson C, Bond L, Burns J, Vells-Brodrick D, Sawyer S. Adolescent resilience: a concept analysis. J Adolesc. 2003;26:1-11.

157. Becerra D, Castillo J. Culturally protective parenting practices against substance use among adolescents in Mexico. J Subst Use. 2011;16:136-49.

158. Draper B, Ridley N, Johnco C, Withall A, Sim W, Freeman M, et al. Screening for alcohol and substance use for older people in geriatric hospital and community health settings. Int Psychogeriatr. 2015;27:157-66.

159. Chen K, Kandel DB. Predictors of cessation of marijuana use: an event history analysis. Drug Alcohol Depend. 1998;50:109-21.

160. Kandel DB, Logan JA. Patterns of drug use from adolescence to young adulthood: periods of risk for initiation, continued use, and discontinuation. Am J Public Health. 1984;74:660-6.

161. Sobell LC, Ellingstad TP, Sobell MB. Natural recovery from alcohol and drug problems: methodological review of the research with suggestions for future directions. Addiction. 2000;95:749-64.

162. Ungar M. Nurturing hidden resilience in at-risk youth in different cultures. J Can Acad Child Adolesc Psychiatry. 2006;15:53-8.

163. Rigsby L. The Americanization of resilience: deconstructing research practice. In: Wang M, Gordon E, editors. Educational Resilience in Inner-City America: Challenges and prospects: Hillsdale: Lawrence Earlbaum associates; 1994. p. 85-94.

164. Luthar S, Doernberger C, Zigler E. Resilience is not a unidimensional construct: insights from a prospective study of inner-city adolescents. Dev Psychopathol. 1993;5:703-17.

165. Luthar SS. Vulnerability and resilience: a study of high-risk adolescents. Child Dev. 1991;62:600-16.

166. Tiet QQ, Huizinga D. Dimensions of the construct of resilience and adaptation among inner-city youth. J Adolesc Res. 2002;17:260-76.

167. Braverman MT. Applying resilience theory to the prevention of adolescent substance abuse. FOCUS a publication of the 4-H Center for Youth Development at the University of California, Davis. 2001. Davis, CA, Department of Human and Community Development, University of California. Available at http://4h.ucanr.edu/files/1232.pdf.

168. Levey EJ, Oppenhelm CE, Lange BCL, Plasky NS, Harris BL, Lekpeh GG, et al. A qualitative analysis of factors impacting resilience among youth in postconflict Liberia. Child Adolesc Psychiatry Ment Health. 2016;10:26.

169. Javdani S, Allen NE. An ecological model for intervention for juvenile justice-involved girls: development and preliminary prospective evaluation. Fem Criminol. 2016;11:135-62.

170. Kurtz SP, Stall RD, Buttram ME, Surratt HL, Chen M. A randomized trial of a behavioral intervention for high risk substance-using MSM. AIDS Behav. 2013;17:2914-26.

171. Pearce ME, Jongbloed KA, Richardson CG, Henderson EW, Pooyak SD,

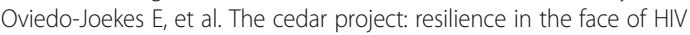
vulnerability within a cohort study involving young indigenous people who use drugs in three Canadian cities. BMC Public Health. 2015;15:1-12.

172. Carrico AW, Gomez W, Siever MD, Discepola MV, Dilworth SE, Moskowitz JT. Pilot randomized controlled trial of an integrative intervention with methamphetamine-using men who have sex with men. Arch Sex Behav. 2015:44:1861-7.

173. Benda BB. Gender differences in predictors of suicidal thoughts and attempts among homeless veterans that abuse substances. Suicide Life Threat Behav. 2005;35:106-16.

174. Markson L, Losel F, Souza K, Lanskey C. Male prisoners family relationships and resilience in resettlement. Criminol Crim Justice. 2015;15:423-41.

175. Werner E. High-risk children in young adulthood: a longitudinal study from birth to 32 years. Am J Orthop. 1989;59:72-81. 
176. Miller E. Reconceptualizing the role of resiliency in coping and therapy. J Loss Trauma. 2003;8:239-46.

177. Roisman $\mathrm{Gl}$. Conceptual clarifications in the study of resilience. Am Psychol. 2005;60:264-5.

178. Johnson JL, Wiechelt SA. Introduction to the special issue on resilience. Subst Use Misuse. 2004;39:657-70.

179. Sutherland JA, Cook L, Stetina P, Hernandez C. Women in substance abuse recovery: measures of resilience and self-differentiation. West J Nurs Res. 2009;31:905-22

180. Pardini DA, Plante TG, Sherman A, Stump JE. Religious faith and spirituality in substance abuse recovery - determining the mental health benefits. J Subst Abus Treat. 2000;19:347-54.

181. Morse N, Thomson LJM, Brown Z, Chatterjee HJ. Effects of creative museum outreach sessions on measures of confidence, sociability and well-being for mental health and addiction recovery service-users. Arts Health Int J Res Polic Pract. 2015;7:231-46.

182. Kidd S, Shahar G. Resilience in homeless youth: the key role of self-esteem. Am J Orthop. 2008;78:163-72.

183. Sirikantraporn S, Mateu-Gelabert P, Friedman SR, Sandoval M, Torruella RA. Resilience among IDUs: planning strategies to help injection drug users to protect themselves and others from HIV/HCV infections. Subst Use Misuse. 2012;47:1125-33.

184. Payne YA. Site of resilience: a reconceptualization of resiliency and resilience in street life-oriented black men. J Black Psychol. 2011;37:426-51.

185. Dalgard O, Egeland A, Skaug K, Vilimas K, Steen T. Health-related quality of life in active injecting drug users with and without chronic hepatitis $C$ virus infection. Hepatology. 2004;39:74-80.

186. Brown RT, Reynolds CR, Whitaker JS. Bias in mental testing since Bias in Mental Testing. Sch Psychol Q. 1999;14:208-38.

187. Carretero M, Burgess A, Soler P, Soler M, Catalan J. Reliability and validity of an HIV-specific health-related quality of life measure for use with injecting drug users. AIDS. 1996;10:1699-705.

188. Falck R, Wang J, Carlson R, Siegal H. Crack-cocaine use and mental health status as defined by the SF-36. Addict Behav. 2000;25:579-84.

189. Haney W. Validity, vaudeville, and values: a short history of social concerns over standardized testing. Am Psychol. 1981;36:1021-34.

190. Mirza HS. Race, gender and IQ: the social consequence of a pseudoscientific discourse. Race Ethn Educ. 1998;1:109-26.

191. O'Malley P, Valverde M. Pleasure, freedom and drugs: the uses of 'pleasure' in liberal governance of drug and alcohol consumption. Sociology. 2004;38:25-42.

192. Haydon E, Fischer B. Crack use as a public health problem in Canada - call for an evaluation of 'safer crack use kits'. Can J Public Health. 2005;96:185-8.

193. Ivsins A, Roth E, Nakamura N, Krajden M, Fischer B. Uptake, benefits of and barriers to safer crack use kit (SCUK) distribution programmes in Victoria, Canada - a qualitative exploration. Int J Drug Policy. 2011;22:292-300.

194. Small D, Drucker E. Return to Galileo? The inquisition of the international narcotic control board. Harm Reduct J. 2008;5:16.

195. Small D. Canada's highest court unchains injection drug users; implications for harm reduction as a standard of health care. Harm Reduct J. 2012;9:34.

196. Symington A. Ottawa: crack pipe program cancelled by city council. HIV AIDS Policy Law Rev. 2007;12:29-30.

197. Best D, Harris J, Gossop M, Farrell M, Finch E, Noble A, et al. Use of nonprescribed methadone and other illicit drugs during methadone maintenance treatment. Drug Alcohol Rev. 2000:19:9-16.

198. Kobasa S. Stressful life events, personality, and health: an inquiry into hardiness. J Pers Soc Psychol. 1979;37:1-11.

199. Marlatt G, Gordon J. Relapse prevention: maintenance strategies in the treatment of addictive behaviours. New York, NY: Guilford Press; 1985.

200. Tebes JK, Irish JT, Vasquez MJP, Perkins DV. Cognitive transformation as a marker of resilience. Subst Use Misuse. 2004;39:769-88.

201. Antonovsky A. Unravelling the mystery of health: how people manage stress and stay well. San-Francisco: Jossey-Bass; 1987.

202. Boyden J, Mann G. Children's risks, resilience, and coping in extreme situations. In: Handbook for working with children and youth: pathways to resilience across cultures and contexts. Thousand Oaks: Sage Publications; 2005. p. 3-26.

203. Yuen $W W-Y$, Wong WC-W, Holroyd E, Tang CS-K. Resilience in work-related stress among female sex workers in Hing Kong. Qual Health Res. 2014;24:1232-41.

204. Burnes TR, Long SL, Schept RA. A resilience-based lens of sex work: implications for professional psychologists. Prof Psychol Res Pr. 2012;43:137-44.
205. Kolar K, Erickson P, Stewart D. Coping strategies of street-involved youth: exploring contexts of resilience. J Youth Stud. 2012;15:744-60.

206. Ferguson KM, Bender K, Thompson SJ. Predictors of transience among homeless emerging adults. J Adolesc Res. 2014;29:213-40.

207. Thompson SJ, Ryan TN, Montgomery KL, Del Pardo Lippman A, Bender K, Ferguson K. Perceptions of resiliency and coping: homeless young adults speak out. Youth Soc. 2016;48:58-76.

208. Werner E, Smith R. Overcoming the odds: high risk children from birth to adulthood. Ithica, NY: Cornell University Press; 1992.

209. Ungar M. Hidden pathways to resilience: how 'Delinquent' behaviour can be a good thing. Cross Curr. 2007;11:8.

210. Ungar M. Researching and theorizing resilience across cultures and contexts. Prev Med. 2012;55:387-9.

211. Furst RT, Johnson BD, Dunlap E, Curtis R. The stigmatized image of the "crack head": a sociocultural exploration of a barrier to cocaine smoking among a cohort of youth in new York City. Deviant Behav. 1999;20:153-81.

212. Inciardi JA. Kingrats, chicken heads, slow necks, freaks, and blood suckers: A glimpse at the Miami sex-for-crack market. In: Ratner MS, editor. Crack pipe as pimp: an ethnographic investigation of sex-for-crack exchanges. New York: Lexington Books; 1993. p. 36-68.

213. Buttram ME, Surratt HL, Kurtz SP. Risk and protective factors associated with personal mastery among sexual minority African-American female sex workers. J Gay Lesbian Soc Serv. 2014;26:407-25.

214. Hartman JL, Turner MG, Daigle LE, Exum ML, Cullen FT. Exploring the gender differences in protective factors: implications for understanding resiliency. Int J Offender Ther Comp Criminol. 2009;53:249-77.

215. Wong MM. Perceptions of parental involvement and autonomy support: their relations with self-regulation, academic performance, substance use and resilience among adolescents. N Am J Psychol. 2008;10:497-518.

\section{Submit your next manuscript to BioMed Central and we will help you at every step:}

- We accept pre-submission inquiries

- Our selector tool helps you to find the most relevant journal

- We provide round the clock customer support

- Convenient online submission

- Thorough peer review

- Inclusion in PubMed and all major indexing services

- Maximum visibility for your research

Submit your manuscript at www.biomedcentral.com/submit
) Biomed Central 